\title{
Catálogo de la flora vascular de los Parques Nacionales de Colombia: Santuario de Flora y Fauna de Iguaque y su zona de amortiguamiento
}

\author{
Catalog of the vascular flora of the National Parks of Colombia: Iguaque Fauna and \\ Flora Sanctuary and buffer zone
}

\section{Humberto Mendoza-Cifuentes}

\begin{abstract}
Resumen
Colombia cuenta con 59 áreas naturales del Sistema Nacional de Parques Nacionales Naturales. El inventario de la flora de estas áreas es insipiente ya que solo se conocen listas publicadas no completas de 13 de ellas. Este es el primer artículo enfocado a publicar información inédita depositada en los herbarios nacionales sobre flora de Parques Nacionales. Se inicia con el Santuario de Flora y Fauna de Iguaque en donde se documenta una lista de 816 especies perteneciente a 141 familias de plantas vasculares. E1 89,5\% de las especies registradas son nativas, dos especies son endémica al Santuario, 30 con posibilidades de ser consideradas Valores Objeto de Conservación, 47 categorizadas en algún riesgo de amenaza y 213 presentan algún tipo de uso actual o potencial.
\end{abstract}

Palabras clave. Colombia. Iguaque. Lista de especies. Los Andes. Parques Nacionales Naturales.

\begin{abstract}
Colombia has 59 natural areas in the System of Natural National Parks. The inventory of the flora of these areas is incipient since only incomplete lists have been published for just 13 of them. This is the first article focused on publishing new information deposited in national herbaria on the flora of National Parks. It starts with the Wildlife and Flora Sanctuary Iguaque where a list of 816 species belonging to 141 families of vascular plants is documented. We found that $89.5 \%$ of the recorded species are native, two species are endemic to the Sanctuary, 30 can possibly considered as Assets Worthy of Conservation, 47 are categorized as being at some risk of threat, and 213 have some type of current or potential use.
\end{abstract}

Key words. Andes. Colombia. Iguaque. National Natural Park. Species check-list.

\section{Introducción}

Colombia cuenta con 59 áreas naturales pertenecientes al Sistema de Parques Nacionales Naturales (PNN), que representan el $12,8 \%$ de la superficie nacional, donde el 11,2 7\% constituye el área continental y 1,5\% el área marina (PNN 2015: http://www. parquesnacionales.gov.co/portal/sistema-de-parques- nacionales-naturales/). Estas áreas de conservación se encuentran distribuidas a lo largo de toda la geografía del país, lo que le confiere al Sistema una alta representatividad ecosistémica y de la biodiversidad de Colombia. 
El Plan de Acción Institucional 2011-2019 (PAI) de Parques Nacionales Naturales de Colombia (PNNC 2011) enfocó parte de sus lineamientos al mapeo de los ecosistemas de las áreas, por lo que la mayoría de los PNN cuentan con mapas e inventario de sus ecosistemas en diferentes escalas asociados a los planes de manejo. Se puede afirmar que al nivel de ecosistemas existe un buen nivel de conocimiento o inventario de los PNN, no obstante, hay un gran desconocimiento de la biodiversidad de especies que albergan.

El inventario de la flora de los PNN en Colombia es bastante incipiente, pues solo se conocen listados o floras publicados de 13 de las 57 áreas con ecosistemas terrestres y existen inventarios relativamente completos y publicados de sólo nueve de ellas (Tabla 1). Esto dificulta el establecimiento y seguimiento de parámetros o indicadores como representatividad de la biodiversidad del Sistema, y limita las posibilidades de establecer valores objeto de conservación apropiados. Igualmente, limita las posibilidades de identificar taxones categorizados en algún nivel de amenaza en estas áreas.

Este trabajo corresponde al primero de una serie de publicaciones que buscan generar información de la flora de los PNN de Colombia bajo la premisa de que en los herbarios nacionales y en algunos extranjeros existe información que puede ayudar a solventar vacíos de conocimiento. La información de los herbarios, completa o incompleta, fragmentada o consolidada, es necesario depurarla y publicarla.

En primera instancia, se inicia con las áreas de conservación mejor representadas en el Herbario FMB del Instituto Alexander von Humboldt, como es el Santuario de Flora y Fauna de Iguaque (SFF Iguaque). Con este estudio se espera dar mérito al nombre de "Santuario de Flora", documentando las especies hasta ahora conocidas para el área y con especímenes de herbario como testigo.

\section{Área de estudio}

El SFF Iguaque se localiza sobre el macizo del mismo nombre y que corresponde a una formación montañosa aislada de aproximadamente 8000 ha, que se despliega entre los 2100 y 3890 m de elevación y que se ubica en jurisdicción de los municipios de Villa de Leiva, Arcabuco, Chíquiza y Sáchica en el departamento de Boyacá (SFF Iguaque 2007; Figura 1). Dentro del macizo, y a partir de la cota de los $2400 \mathrm{~m}$ de elevación, se encuentra el SFF Iguaque, con una extensión de 6.923 ha (SFF Iguaque 2007, PNNC 2015 en: http://www.parquesnacionales.gov. co/portal/ecoturismo/region-andina/santuario-deflora-y-fauna-iguaque/). Por debajo de esta cota, se encuentra el área de amortiguamiento (en proceso de reglamentación), que cubre el área restante del macizo.

El área tiene una representación de la vegetación andina de tipo matorral subxerofítico, bosque andino, bosque altoandino, subpáramo y páramo de acuerdo con la clasificación de Van der Hammen y Rangel-Ch. (1997) (Figura 2). Los bosques andinos están conformados de variantes de bosques de roble (dominados por Quercus humboldtii) y bosques mixtos en donde no se encuentra una especie claramente dominante. Algunos sectores cercanos a Villa de Leyva, originalmente correspondían a bosques de gaque (Clusia multiflora). Los matorrales subxerofíticos son arbustales dominados por el hayuelo (Dodonaea viscosa).

Actualmente, por causa de múltiples incendios forestales desde la época de la colonia y el cambio de las condiciones climáticas, en buena parte del macizo la vegetación original ha sido reemplaza por sabanas en un proceso conocido como "sabanización" (O. Vargas com. per.). En estas sabanas de montaña predominan especies invasoras de pastos, helechos y especies provenientes de zonas de subpáramo y páramo, todas adaptadas a condiciones de fuego (pirófilas). Por ejemplo, en toda la vertiente norte del macizo entre el municipio de Sáchica y Villa de Leyva predominan pastizales dominados por dos especie de gramíneas foráneas para la zona: el pasto yaraguá (Melinis minutiflora, proveniente de África) y el rabo de zorro de montaña (Andropogon lehmannii, nativa de Colombia pero con comportamiento invasor). 
Tabla 1. Parques Nacionales Naturales de Colombia con inventarios florísticos publicados.

\begin{tabular}{|c|c|c|c|}
\hline Regional / Área de Conservación & $\begin{array}{l}\text { No. } \\
\text { Especies }\end{array}$ & Fuente & $\begin{array}{l}\text { Invetario } \\
\text { relativamente } \\
\text { completo }\end{array}$ \\
\hline \multicolumn{4}{|l|}{ Regional Amazonía } \\
\hline Reserva Nacional Natural Puinawai & 688 & Córdoba y Etter (2001) & \\
\hline Reserva Nacional Natural Nukak & 628 & Córdoba et al. (2001) & \\
\hline $\begin{array}{l}\text { Parque Nacional Natural Serranía de } \\
\text { Chiribiquete }\end{array}$ & 528 & Estrada y Fuertes (1993), Cortes (1996) & \\
\hline Parque Nacional Natural Amacayacu & 1348 & Rudas y Prieto (2005) & $\mathrm{X}$ \\
\hline \multicolumn{4}{|l|}{ Regional Andes Nororientales } \\
\hline Santuario de Flora y Fauna Iguaque & 816 & Presente trabajo & $\mathrm{X}$ \\
\hline \multicolumn{4}{|l|}{ Regional Andes Occidentales } \\
\hline Parque Nacional Natural Las Orquídeas & 1318 & $\begin{array}{l}\text { Pedraza-Peñalosa, P. y J. Betancur (2015) } \\
\text { onward. Flora of Las Orquídeas National Park: } \\
\text { vascular plants of the Colombian Andes and } \\
\text { Chocó (http://sweetgum.nybg.org/orquideas). } \\
\text { The New York Botanical Garden, Bronx, New } \\
\text { York. }\end{array}$ & $\mathrm{X}$ \\
\hline \multicolumn{4}{|l|}{ Regional Caribe } \\
\hline Parque Nacional Natural Macuira & 349 & Sudgen y Forero (1982) & $\mathrm{X}$ \\
\hline Parque Nacional Natural Tayrona & 685 & Lozano (1986) & $\mathrm{X}$ \\
\hline \multicolumn{4}{|l|}{ Regional Orinoquía } \\
\hline Parque Nacional Natural Chingaza & $\begin{array}{c}534 \\
(441)\end{array}$ & $\begin{array}{l}\text { Rangel-Ch. (2000), Madriñan et al. (2015) } \\
\text { consultado en http://chingaza.uniandes.edu. } \\
\text { co/FIC/article.html\#Anchor-Resumen-47857 }\end{array}$ & \\
\hline Parque Nacional Natural El Tuparro & 828 & Barbosa (1992), Mendoza (2007) & $\mathrm{X}$ \\
\hline Parque Nacional Natural Sumapaz & $\begin{array}{c}860 \\
(619)\end{array}$ & Franco y Betancur (1999), (Rangel-Ch. 2000) & $\mathrm{X}$ \\
\hline \multicolumn{4}{|l|}{ Regional Pacífico } \\
\hline Parque Nacional Natural Munchique & 745 & Lozano et al. (1996) & \\
\hline $\begin{array}{l}\text { Parque Nacional Natural Farallones de } \\
\text { Cali }\end{array}$ & $?$ & Calderón (1994) & \\
\hline Santuario de Flora y Fauna Malpelo & 28 & González-Roman et al. (2014) & $\mathrm{X}$ \\
\hline Parque Nacional Natural Gorgona & $\begin{array}{c}400 \\
(512)\end{array}$ & Barbosa (1986), (Murillo y Lozano 1989) & $\mathrm{X}$ \\
\hline
\end{tabular}




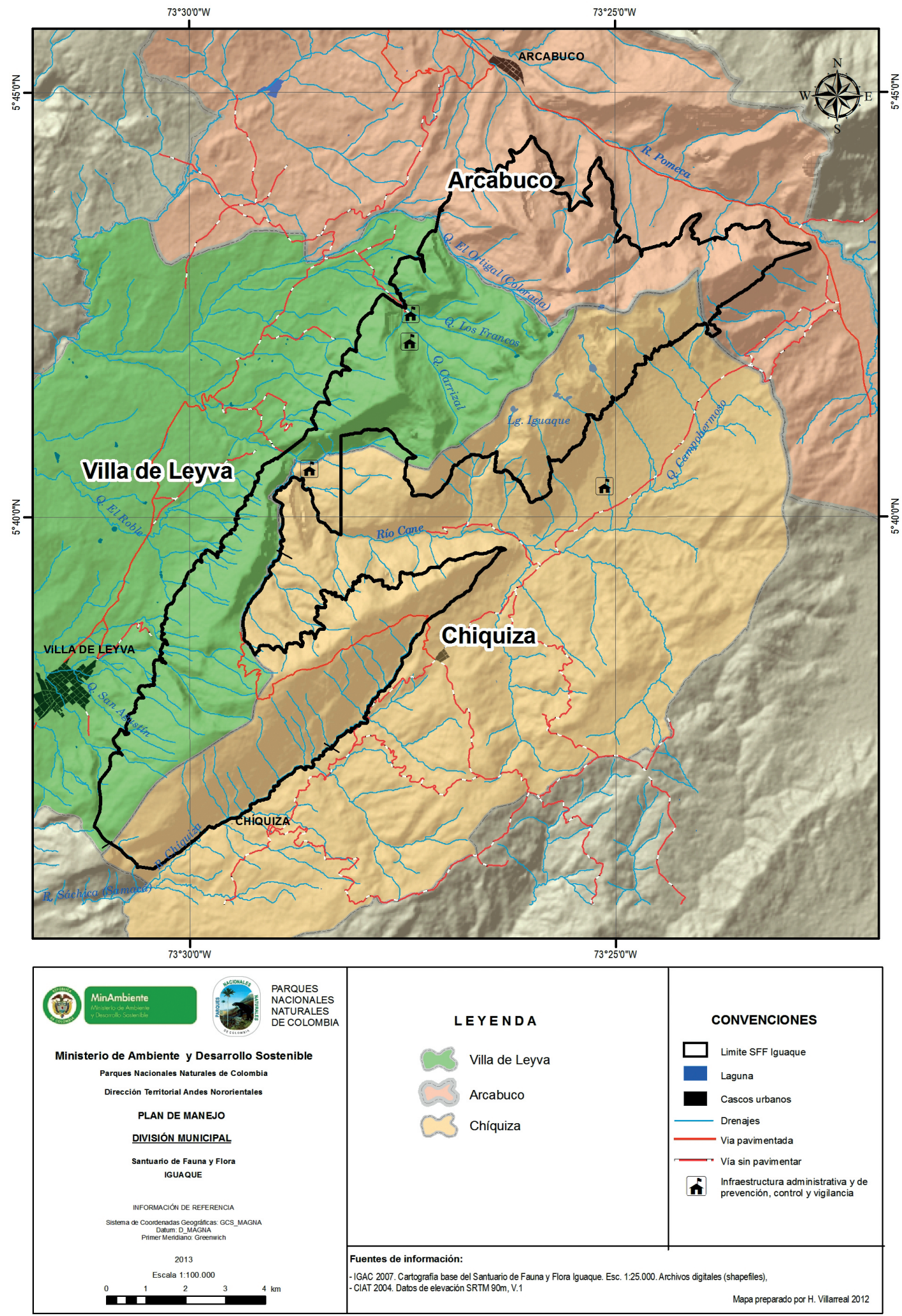

Figura 1. Mapa del Macizo de Iguaque con ubicación del SFF Iguaque y municipios asociados, Boyacá, Colombia. Fuente: SFF Iguaque (2015). 

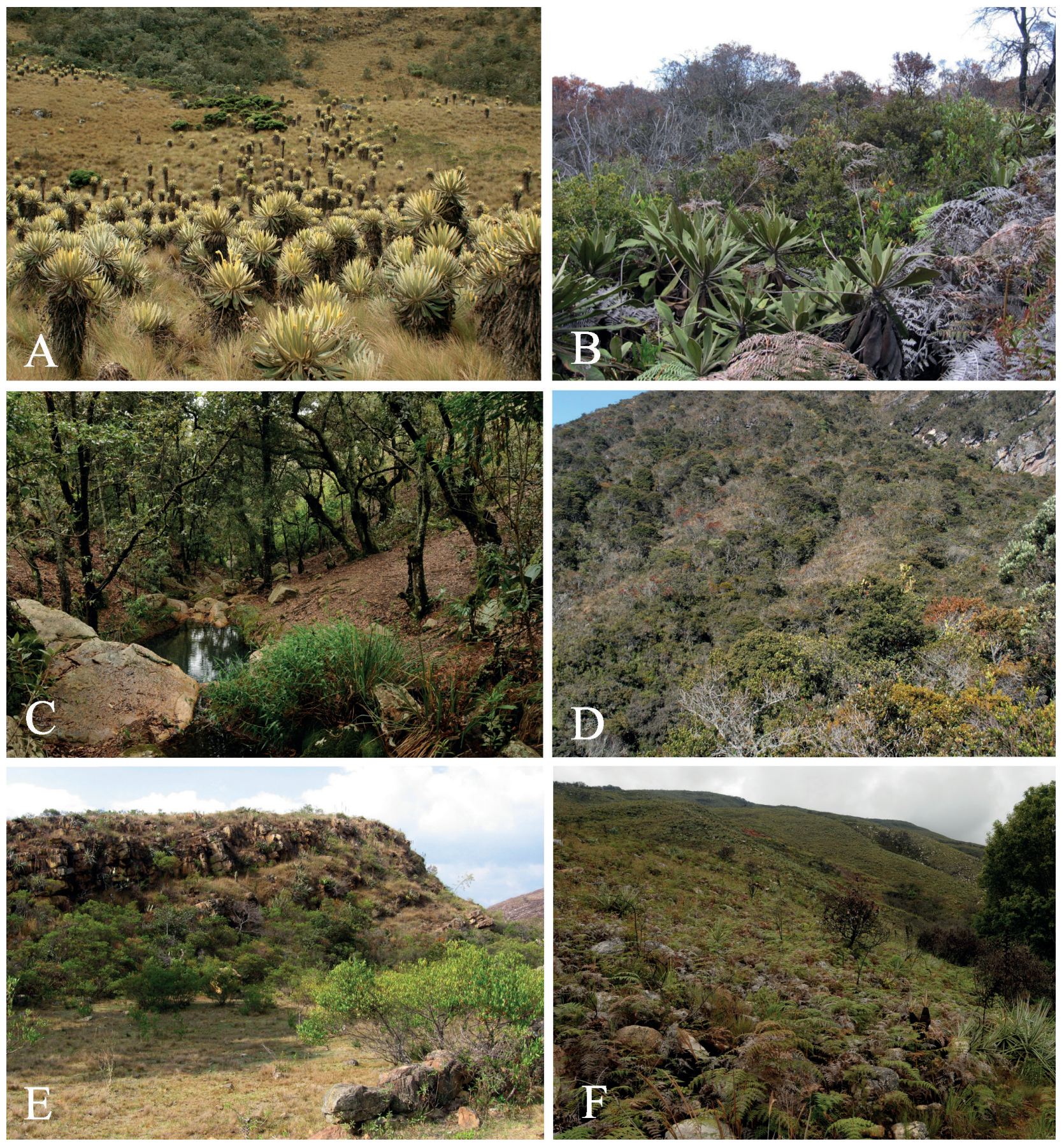

Figura 2. Tipos de vegetación en el Macizo de Iguaque. A). Páramo; B). Subpáramo; C). Robledal (bosque andino); D). Encenillal (bosque altoandino); E). Matorral subxerifítico; F). Zona intervenida y sabanizada. Fotos: A, B, E, F) H. Mendoza; D) H. Villarreal; C) J. Salas. 


\section{Métodos}

Se realizó una lista de especies de plantas vasculares del SFF Iguaque con base en la información depositada en los herbarios Nacional Colombiano (COL) y Federico Medem Bogotá (FMB). Estos dos herbarios concentran la mayor cantidad de colecciones del macizo de Iguaque, y mantienen un proceso activo de curadoría. Para algunos pocos casos específicos y en donde no se contaron con colecciones de herbario pero se constató la presencia de la especies en el área de estudio, se utilizó como referencia la publicación de González (2014) sobre flora de Villa de Leyva. Las colecciones del herbario FMB fueron revisadas exhaustivamente, determinadas y posteriormente fotografiadas. Las colecciones del Herbario COL fueron consultadas en línea (Instituto de Ciencias Naturales, Facultad de Ciencias, Universidad Nacional de Colombia. http://www.biovirtual.unal.edu.co/ $\mathrm{ICN} /$ ? controlador $=$ Forms $\&$ accion $=$ quickForm Scientific \& group $=1 \&$ search Type $=$ scientific Consultado enero-febrero de 2015), y las imágenes confrontadas con los ejemplares del herbario FMB con la finalidad de establecer errores de diferentes nombres puestos a un mismo taxón o viceversa. La mayor parte de los ejemplares y sus determinaciones se constataron en la base de datos Plant Type Specimens Database of The Global Plants Initiative en JSTOR (http://plants.jstor.org/search?plantName).

La totalidad de los nombres fueron confrontados con el catálogo de plantas de Colombia (Bernal et al. 2016) y la base de datos Tropicos (Missouri Botanical Garden. 20 Feb 2015. Tropicos.org. http://www. tropicos.org). Para las familias de Angiospermas y el agrupamiento de géneros se siguió la propuesta del APG III (Stevens, P. F. 2001 onwards. Angiosperm Phylogeny Website. Version 12, July 2012. http:// www.mobot.org/MOBOT/research/APweb/).

En la lista se establecieron los siguientes campos de información:

- Colección de referencia y herbario de procedencia.

- Hábito de crecimiento. Con base en la información de las etiquetas.
- Hábitat. Con base en la información de las etiquetas y agrupándolas en grandes hábitats comunes en el área. En el área se encuentran zonas de vegetación nativa de matorrales (vegetación herbácea en regeneración temprana), arbustales (asociados a las zonas secas y subpáramos), bosques (mixtos) o de roble (robledal), y páramo. También se encuentran zonas muy intervenidas donde se pueden discriminar ambientes asociados a bordes (de bosque, caminos o quebradas), zonas abiertas (poteros, áreas pedregosas), zonas de cultivos, jardines, cercas vivas, así como algunas plantaciones y zonas anegadas. En esta parte no se consideró el tipo de vegetación de acuerdo a propuestas nacionales debido a la dificultad de inferir esta información sin contar con la georeferenciación de todas las colecciones y por la dificultad de asociar a un tipo de vegetación especies de zonas intervenidas.

- Localidad. Para el área de estudio buena parte de las localidades se englobaron en grandes zonas como Villa de Leyva (área de amortiguamiento de las microcuencas San Francisco, San Agustín, Tintales y la Colorada, parte del camino a La Hondura hasta el boquerón del río Cane); Capilla (la zona de amortiguamiento entre el boquerón del Cane hasta cerca de quebrada Mamaramos); Arcabuco (zona de amortiguamiento en este municipio incluyendo la vereda Rupavita); Ritoque (zona de amortiguamiento del área seca y límites con Sáchica); San pedro de Iguaque y Chíquiza (zona de amortiguamiento en este último municipio); Morro Negro (parte alta de La Hondura); SFF Iguaque (toda la zona del Santuario correspondiente a la sede administrativa en Carrizales, quebrada Mamaramos, zonas de las lagunas y senderos).

- Elevación. En caso de encontrarse un solo registro de elevación pero donde se conoce que la especie se encuentra en otros rangos se colocó el signo " $>$ mayor que".

- Origen. Se especifica si la especie es nativa de Colombia o introducida, ya sea naturalizada o cultivada, con base en el Catálogo de Plantas de Colombia (Bernal et al. 2016). Para la familia Poaceae se corroboró esta información con el catálogo para Colombia (Giraldo-Cañas 2013). 
- Nombres locales. Con base en la información de las etiquetas.

- Uso actual o potencial. Con base en la información de las etiqueta. En el caso de especies con potencial en restauración la información se basó en la experiencia del autor.

- Grado de amenaza. Con base en los Libros Rojos de Plantas Amenazadas de Colombia y literatura disponible: Asteraceae (Calderón et al. 2005), Bromeliaceae, Lamiaceae y Passifloraceae (García y Galeano 2006), Especies maderables (Cárdenas y Salinas 2007) y Orchidaceae (Calderón-Sáenz 2007).

\section{Resultados y discusión}

Para el SFF Iguaque y su zona de amortiguamiento se registran 816 especies agrupadas en 141 familias (Anexo 1). De éstas, el 89,5\% corresponden a especies nativas de Colombia y el 10,4\% a especies introducidas ya sean cultivadas, naturalizadas o invasoras (Tabla 2). Se encontraron 187 especies con algún uso o potencial de uso, 80 de las cuales tienen potencial para la restauración ecológica (Tabla 2). Al nivel de conservación, se proponen 30 especies con potencial para utilizase como valores objeto de conservación, ya sea por su rareza, grado de amenaza, sobre-explotación o endemicidad. Se documentan 47 especies categorizadas con algún grado de amenaza (Tabla 2).

Dos especies son endémicas del área de estudio: Oliveriana ortizii Fernández (Orchidaceae) y
Pilostyles boyacensis F. González y Pabón-Mora. Este último registro es el más relevante pues es el primero y único registro conocido de la familia Apodanthaceae para Colombia y representa una nueva especie recientemente descrita (González y Pabón-Mora 2014).

El trabajo de González (2014), sobre la flora del municipio de Vila de Leiva y alrededores, es bastante completo, pues relaciona 1293 especies de plantas vasculares nativas y otras exóticas cultivadas como comestibles u ornamentales. Con la presente lista, el trabajo de González (op cit.) comparte el $55 \%$ de las especies y documenta 477 nombres de especies adicionales. De este trabajo, en la presente lista se retoman cinco registros, los cuales no cuenta con ejemplares de herbario para el área de estudio pero hay plena seguridad de su presencia y de su identidad taxonómica: Agave americana, Furcraea cabuya (cabuya), Tillandsia usneoides (barbas de viejo), Vasconcellea pubescens (papayuela) y Tropaeolum tuberosum (navo).

Las diferencias del número de especies entre los dos trabajos es producto de la metodología. La lista que se presenta se basa exclusivamente en nombres que cuentan con ejemplares de herbario como evidencia. Parte de las especies documentadas en González (2014) no cuentan con ejemplares como evidencia y corresponde a especies exóticas cultivadas. 
Tabla 2. Especies de plantas en el SFF de Iguaque y su área de amortiguamiento, Boyacá, Colombia. Número de especies por grupo taxonómico, hábitos de crecimiento, endemismos, valor de conservación, categoría de amenaza y uso.

\begin{tabular}{|c|c|c|c|}
\hline Item & Nativas & Introducidas & Total \\
\hline \multicolumn{4}{|l|}{ Grupo } \\
\hline Plantas con flores & 649 & 84 & 733 \\
\hline Helecho, Selaginelas y Licopodios & 78 & 0 & 78 \\
\hline Pinos & 3 & 2 & 5 \\
\hline \multicolumn{4}{|l|}{ Hábito de crecimiento } \\
\hline Árbol & 86 & 14 & 100 \\
\hline Arbusto & 177 & 14 & 191 \\
\hline Hierbas & 398 & 54 & 452 \\
\hline Lianas y bejucos & 60 & 4 & 64 \\
\hline Bambusoides & 2 & 0 & 2 \\
\hline Holo/hemiparásitas & 7 & 0 & 7 \\
\hline Endémicas & 2 & & 2 \\
\hline Con posibilidades de Valores Objeto de Conservación & 29 & & 29 \\
\hline \multicolumn{4}{|l|}{ Amenazadas } \\
\hline EN & 5 & & 5 \\
\hline NT & 5 & & 5 \\
\hline VU & 3 & & 3 \\
\hline LC & 33 & & 33 \\
\hline \multicolumn{4}{|l|}{ Uso } \\
\hline Alimenticio & 18 & 14 & 32 \\
\hline Medicinal & 37 & 5 & 42 \\
\hline Ornamental & 25 & 10 & 35 \\
\hline Restauración & 70 & 9 & 79 \\
\hline Otros & 7 & 7 & 14 \\
\hline
\end{tabular}




\section{Agradecimientos}

Expreso mis agradecimientos a Claudia Medina (Coordinadora de Colecciones Biológicas del Instituto Alexander von Humboldt) por su apoyo a la curaduría de las colecciones del Instituto Humboldt. A las asistentes del Herbario FMB, Aura Robles y Janet Robles, por la ayuda en la revisión, organización y sistematización de colecciones. A Héctor Villareal por el suministro del mapa. Al Instituto Alexander von Humboldt por apoyar la línea de investigación en biodiversidad de los PNNC.

\section{Literatura citada}

Barbosa, C. 1986. Contribución al conocimiento de la flora y vegetación del Parque Nacional Natural Isla de Gorgona y Gorgonilla. Revista Perez-Arbelaezia 1(3): 311-335.

Barbosa, C. 1992. Contribución al conocimiento de la flórula del PNN El Tuparro. Inderena. Biblioteca Andrés Posada Arango. Libro 3. Bogotá, D.C., Colombia. $271 \mathrm{pp}$.

Bernal, R., S. R. Gradstein y M. Celis (Eds.) 2016. Catálogo de plantas y líquenes de Colombia. Instituto de Ciencias Naturales, Universidad Nacional de Colombia, Bogotá. 3060 pp.

Calderón, E. 1994. Flora de plantas vasculares de alta montaña en los Farallones de Cali, y sus relaciones biogeográficas. Cespedesia 20(66): 9-34.

Calderón, E., G. Galeano y N. García (Eds.) 2005. Libro Rojo de Plantas de Colombia. Volumen 2. Palmas, frailejones y zamias. Serie Libros Rojos de Especies Amenazadas de Colombia. Bogotá, Colombia. Instituto Alexander von Humboldt - Instituto de Ciencias Naturales de la Universidad Nacional de Colombia - Ministerio de Ambiente, Vivienda y Desarrollo Territorial. 454 pp.

Calderón-Sáenz, E. (Ed.) 2007. Libro Rojo de Plantas de Colombia. Volumen 6. Orquídeas. Serie Libros Rojos de Especies Amenazadas de Colombia. Bogotá, Colombia. Instituto Alexander von Humboldt - Instituto de Ciencias Naturales de la Universidad Nacional de Colombia - Ministerio de Ambiente, Vivienda y Desarrollo Territorial. 454 pp.

Cárdenas L., D. y N. R. Salinas (Eds.) 2007. Libro Rojo de Plantas de Colombia. Volumen 4. Especies maderables amenazadas: primera parte. Serie Libros Rojos de Especies Amenazadas de Colombia. Bogotá, Colombia. Instituto Amazónico de Investigaciones
Científicas SINCHI - Ministerio de Ambiente, Vivienda y Desarrollo Territorial. 232 pp.

Córdoba, M. y A. Etter. 2001. Flora. Reserva Nacional Natural Puinawai. 102-208 p. En: Etter, A. (Ed.) Puinawai y Nukak - Caracterización ecológica de dos reservas nacionales naturales de la Amazonia colombiana. IDEADE, Universidad Javeriana. 832 pp.

Córdoba, M., A. Etter y H. Mendoza. 2001. Flora. Reserva Nacional Natural Nukak. 204-208 Pp. En: Etter, A. (Ed.) Puinawai y Nukak - Caracterización ecológica de dos reservas nacionales naturales de la Amazonia colombiana. Ideade, Universidad Javeriana. 832 pp.

Cortés, R. 1996. Análisis pangeográfico de la flora de Chiribiquete, Colombia. Caldasia 19 (3): 465-478.

Estrada, J. y J. Fuertes. 1993. Estudios botánicos en la Guyana Colombiana IV. Notas sobre la vegetación y Flora de la Sierra de Chiribiquete. Revista de la Academia Colombiana de Ciencias Exactas, Físicas y Naturales 18 (71): 483-497.

Franco, P. y J. Betancur. 1999. La flora del Alto Sumapaz (Cordillera Oriental, Colombia). Revista de la Academia Colombiana de Ciencias Exactas, Físicas y Naturales 23: $53-78$.

García, N. y G. Galeano (Eds.) 2006. Libro Rojo de Plantas de Colombia. Volumen 3. Las bromelias, las labiadas y las pasifloras. Serie Libros Rojos de Especies Amenazadas de Colombia. Bogotá, Colombia. Instituto Alexander von Humboldt - Instituto de Ciencias Naturales de la Universidad Nacional de Colombia - Ministerio de Ambiente, Vivienda y Desarrollo Territorial. 679 pp.

Giraldo-Cañas, D. 2013. Las gramíneas de Colombia Riqueza, distribución, endemismos, invasión, migración, usos y taxonomías populares. Biblioteca José Jerónimo Triana 26: 13-382.

González, F. 2014. Villa de Leyva florece. Guía ilustrada de plantas de Villa de Leyva y alrededores. Bogotá. $412 \mathrm{pp}$.

González, F. y N. Pabón Mora. 2014. Pilostyles boyacensis, a new species of Apodanthaceae (Cucurbitales) from Colombia. Phytoyaxa 178 (2): 138-145.

González-Román, R. D., M. López y P. A SilverstoneSopkin. 2014. Flora terrestre de la Isla de Malpelo, Colombia, Pacífico Tropical Oriental. Revista de Biología Tropical 62 (1): 327-336.

Lozano, G. 1986. Comparación florística del parque nacional natural Tayrona, La Guajira y la Macuira Colombia, y Los Medanos de Coro - Venezuela. Mutisia 67: 1-26.

Lozano, G., G. Ruiz, F. A. González y M. T. Murillo. 1996. Diversidad vegetal del Parque Nacional de Munchique, 
Cauca, Colombia (Entre 1800 y 3050 msnm). Biblioteca José Jerónimo Triana 13: 9-64.

Mendoza, H. 2007. Vegetación. Pp. 53-86. En: Villarreal-Leal, H. y J. Maldonado-Ocampo. (Comp.). Caracterización biológica del Parque Nacional Natural El Tuparro (Sector noreste), Vichada, Colombia. Instituto de Investigación de Investigación de Recursos Biológicos Alexander von Humboldt. Bogotá D.C., Colombia.

Murillo, M. T. y G. Lozano 1989. Hacia la realización de una flórula del Parque Nacional Natural Islas de Gorgona y Gorgonilla, Cauca, Colombia. Revista de la Academia Colombiana de Ciencias Exactas, Físicas y Naturales 17 (65): 277-304.

PNNC - Parques Nacionales Naturales de Colombia. 2011. Plan de Acción Institucional Parques Nacionales Naturales de Colombia 2011 - 2019. Bogotá, Colombia. $57 \mathrm{pp}$.

Rangel- Ch., O. 2000. Catálogo florístico de los Macizos de Chingaza y Sumapaz. Pp: 563-598. En: Rangel-Ch., J. O. (Ed.). Colombia Diversidad Biótica III, La región de vida paramuna. Universidad Nacional de Colombia, Facultad de Ciencias, Instituto de Ciencias Naturales. Bogotá.
Rudas, A. y A. Prieto. 2005. Flórula del Parque Nacional Natural Amacayacu, Amazonas, Colombia. Monographs in Systematic Botany from the Missouri Botanical Garden, Vol. 99. 680 pp.

SFF Iguaque. 2007. Plan de Manejo 2005-2009, Resumen Ejecutivo. Convenio Instituto Humboldt-Parques nacionales, Subcomponente Planes de Manejo, Proyecto Andes. 48 pp.

Santuario de Flora y Fauna de Iguaque - SFF Iguaque. 2015. Plan de Manejo 2015-2020. Parques Naturales Nacionales de Colombia, (en proceso).

Sugden, A. M. y E. Forero, 1982. Catálogo de las plantas vasculares de la Guajira con comentarios sobre la vegetación de la Serranía de la Macuira. Colombia Geográfica 10 (1): 23-75.

Van der Hammen, T. y J. O. Rangel-Ch. 1997. El estudio de la vegetación en Colombia. Pp. 17-57. En: Rangel, O., P. D. Lowy y M. Aguilar (Eds.). Colombia - Diversidad Biótica II - Tipos de vegetación. Instituto de Ciencias Naturales/Universidad Nacional de Colombia; Instituto de Hidrología, Meteorología y de Estudio Ambientales Ideam. Bogotá. 436 pp. 
ะึ.

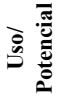

产

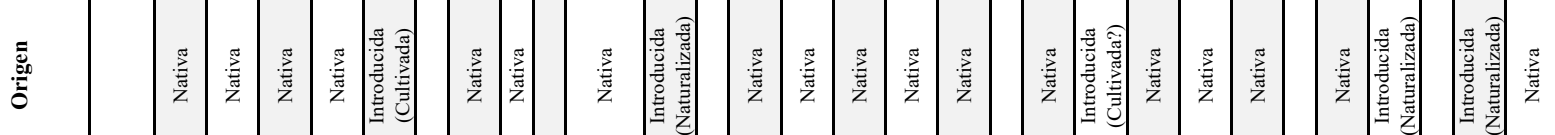

童竞离

离

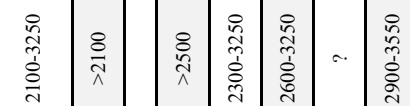

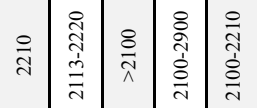

先

:

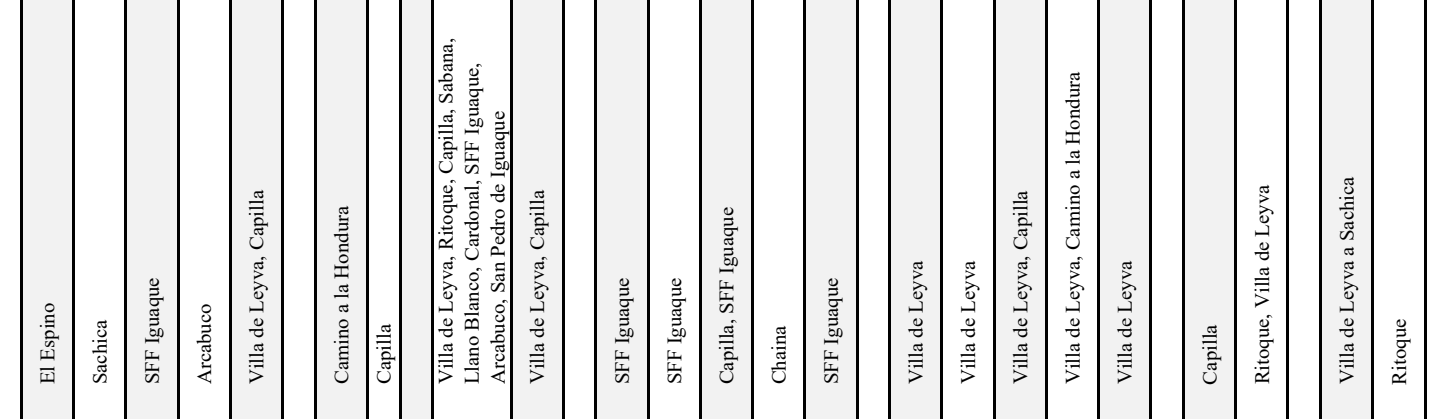

离 芠

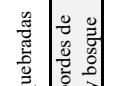

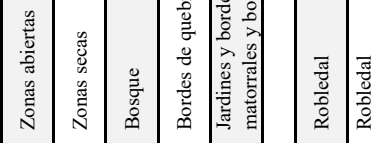

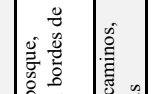

$\frac{\sqrt{2}}{3 \sqrt{3}}$

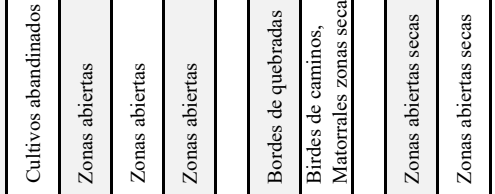

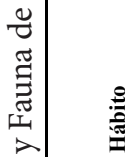

ฯ

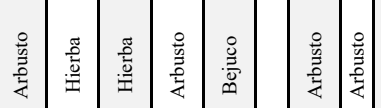

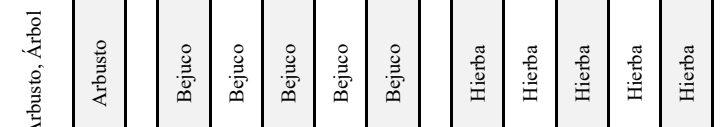

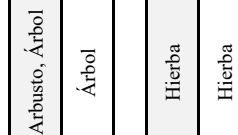



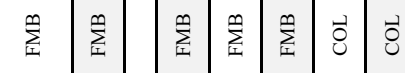

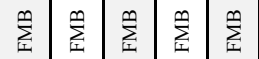

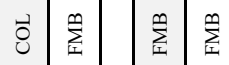



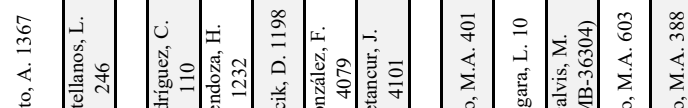

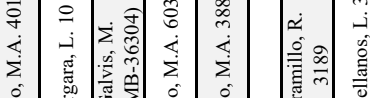

倠



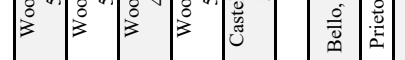

¿

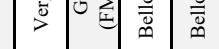

遥

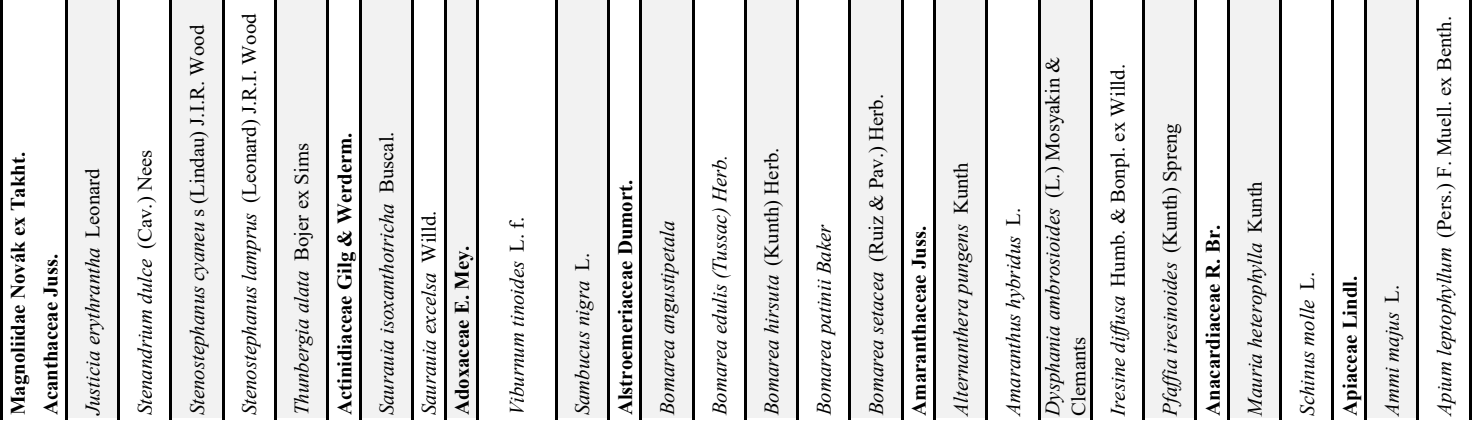

吾 







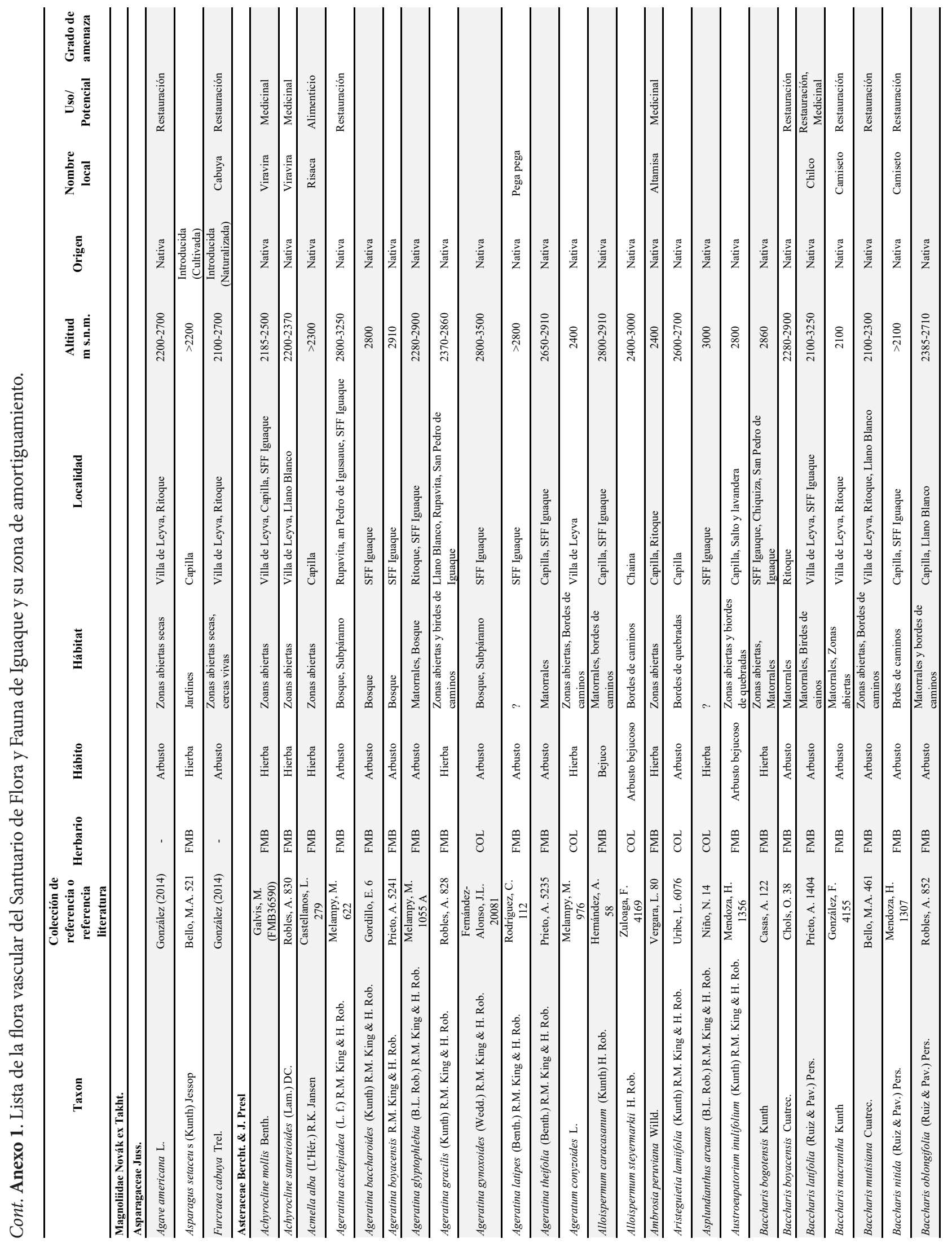




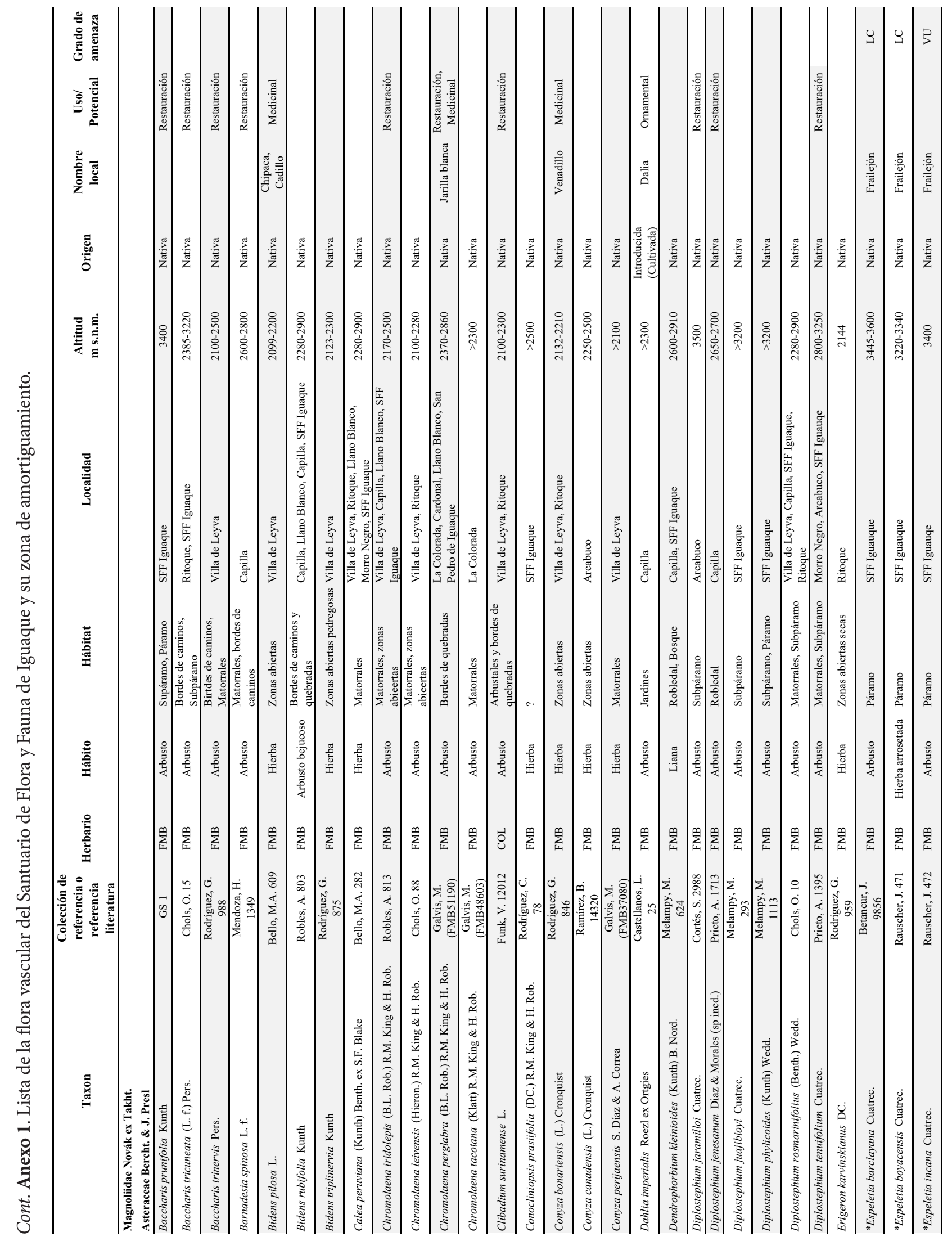




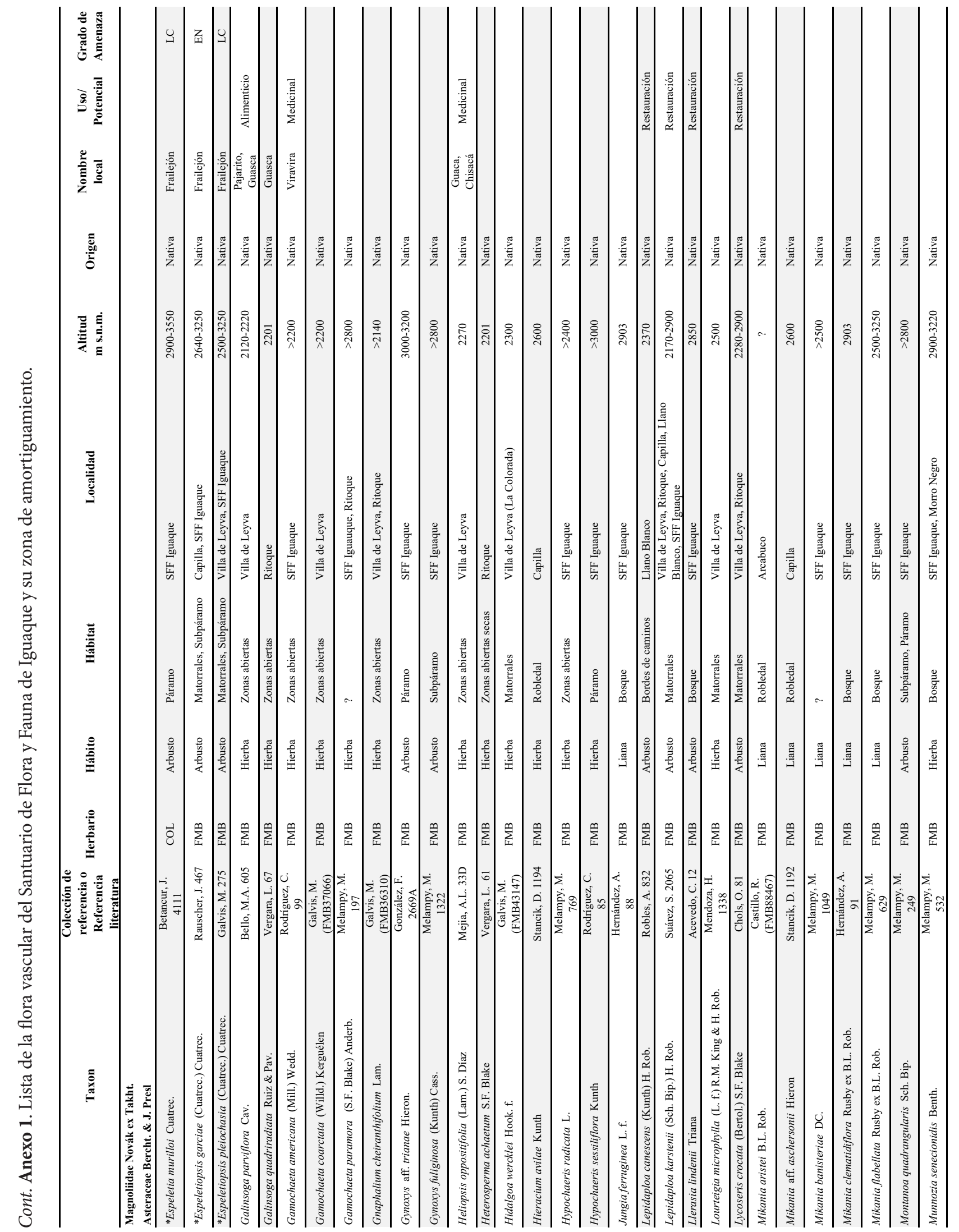




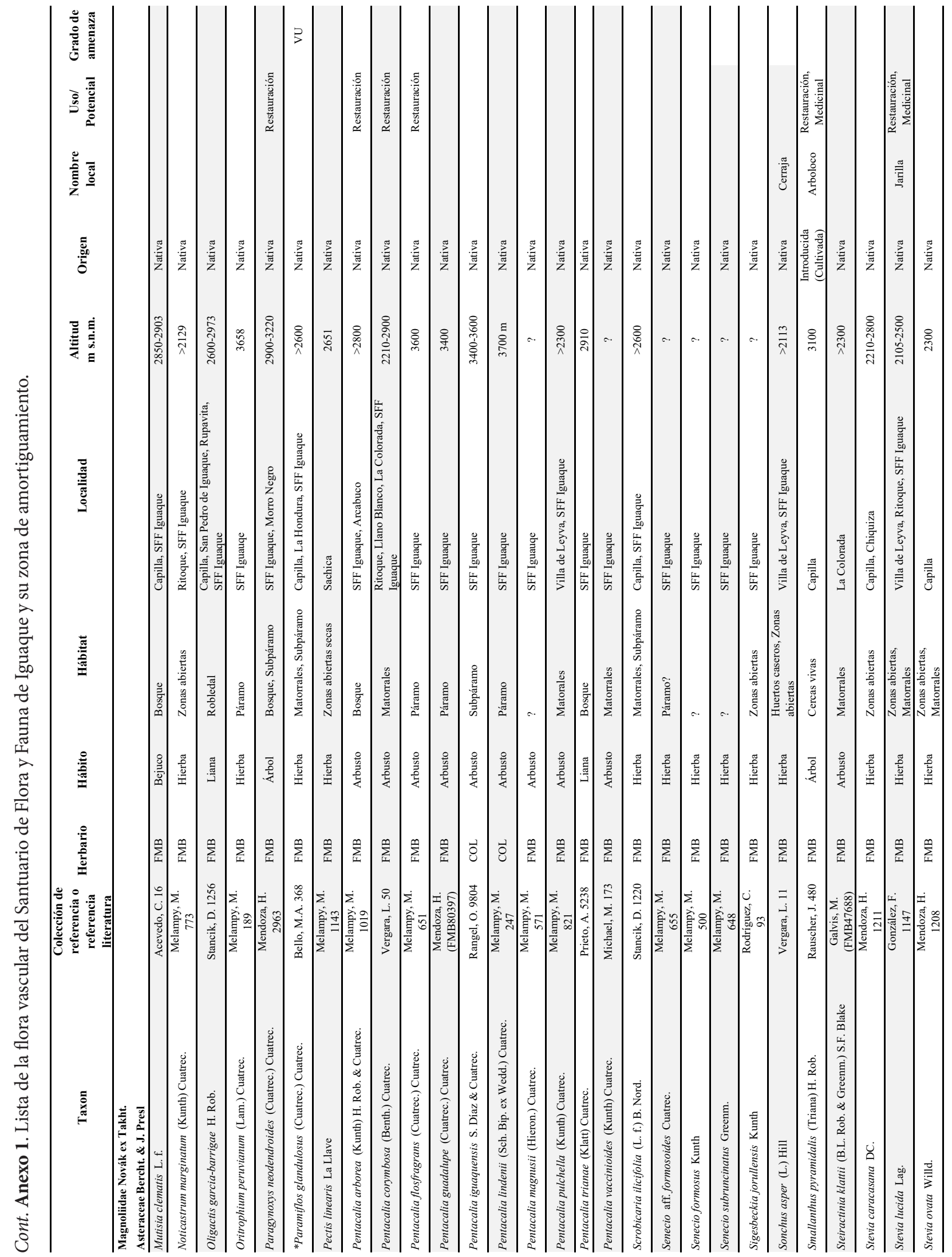




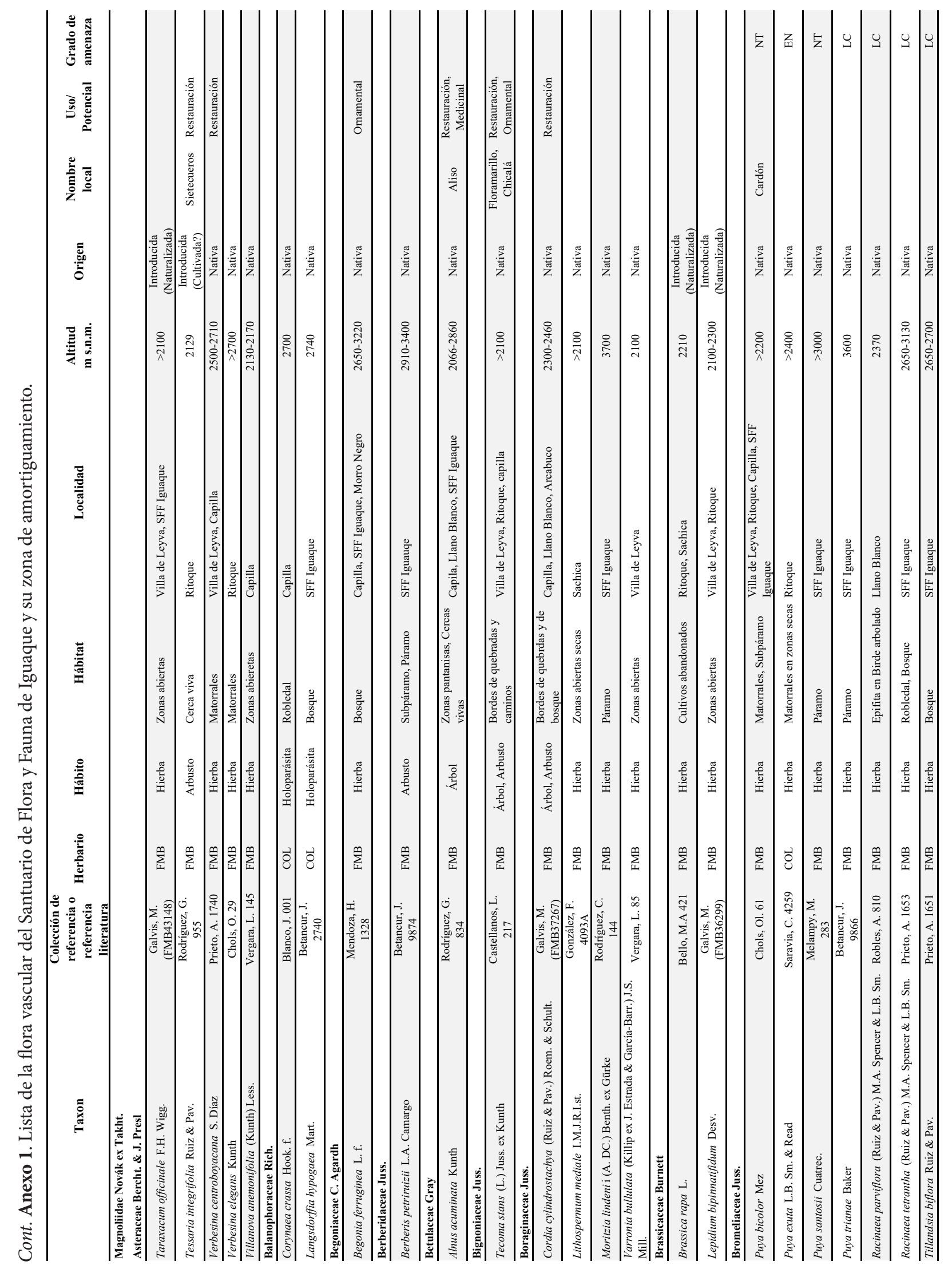




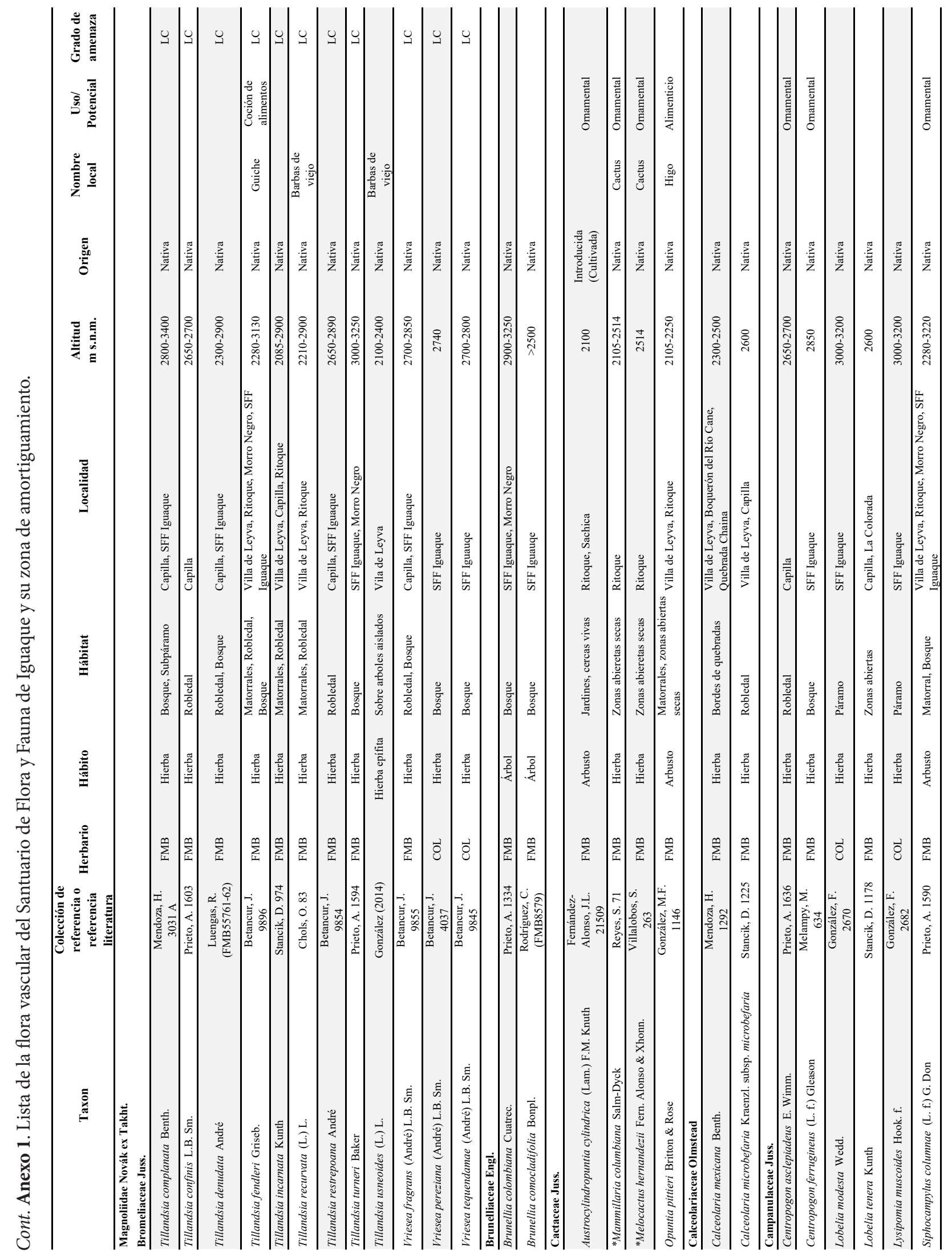




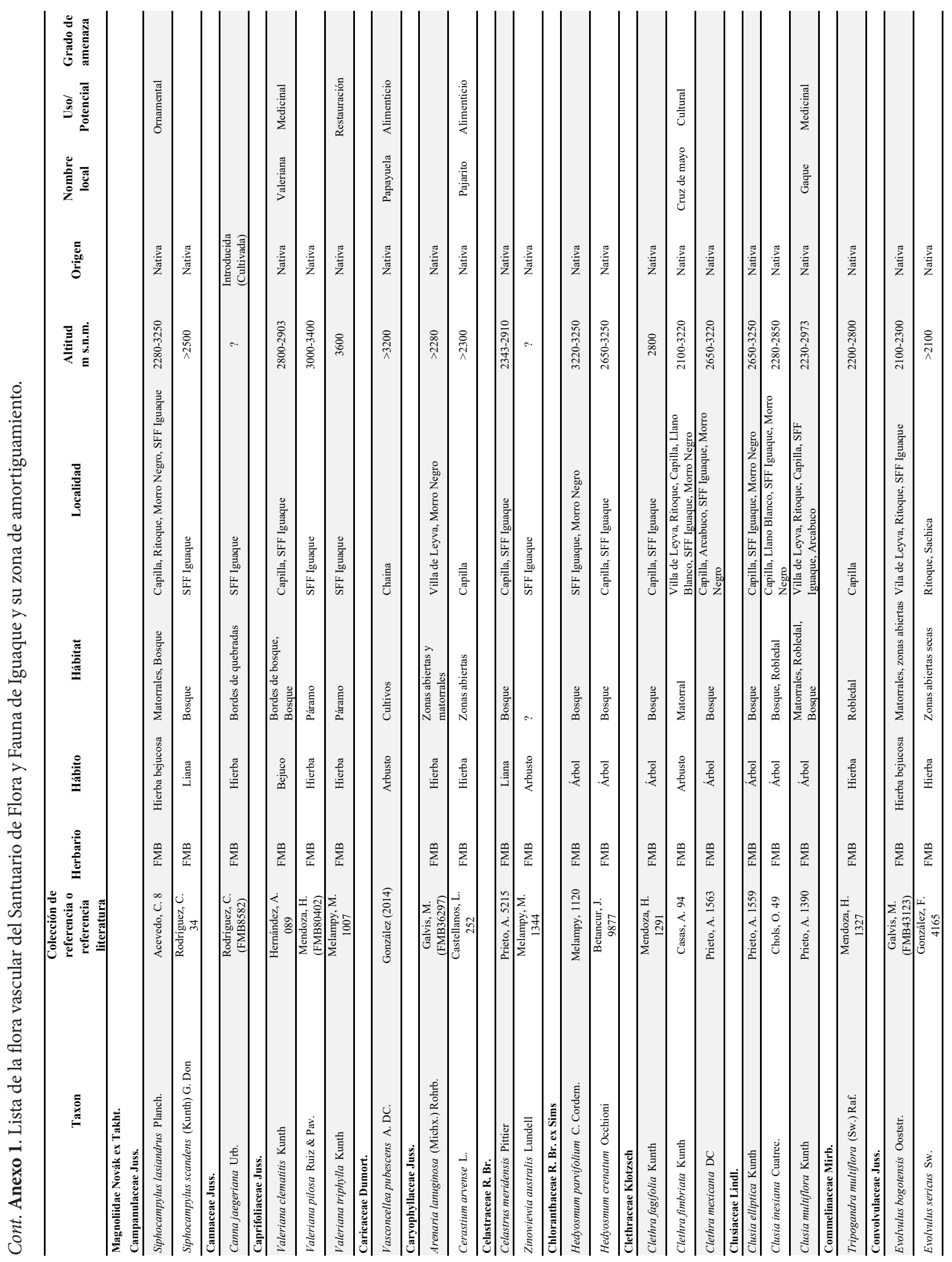




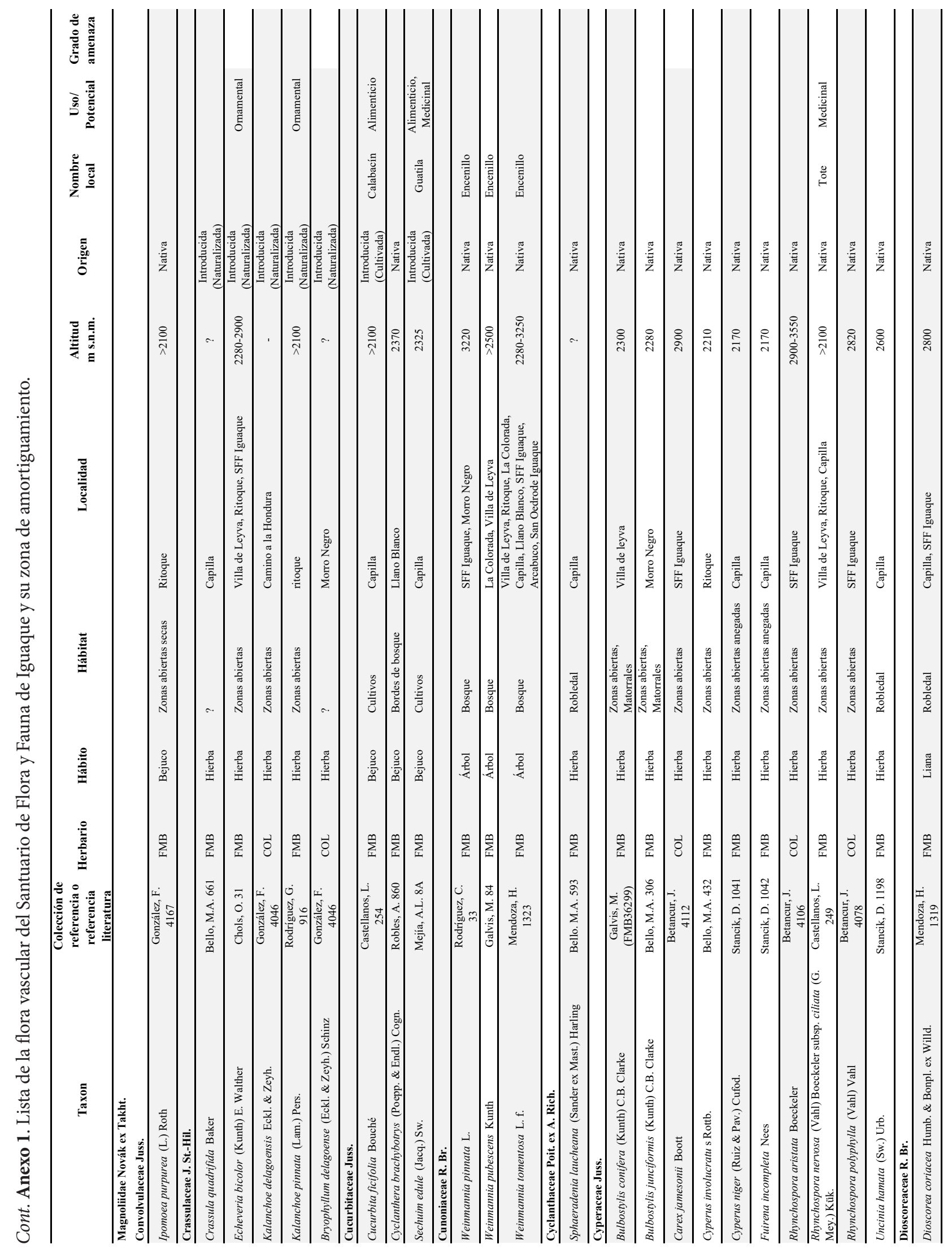




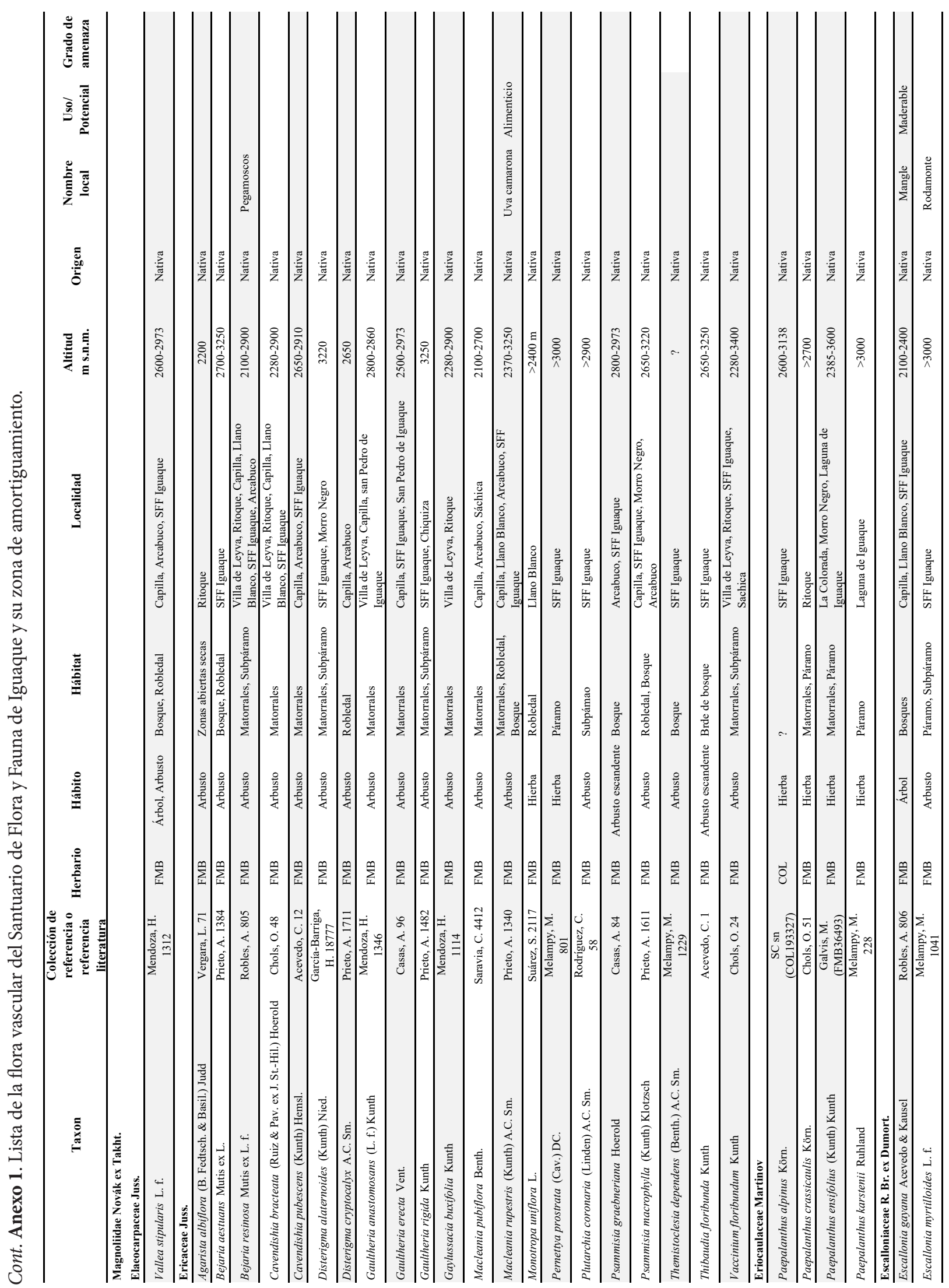




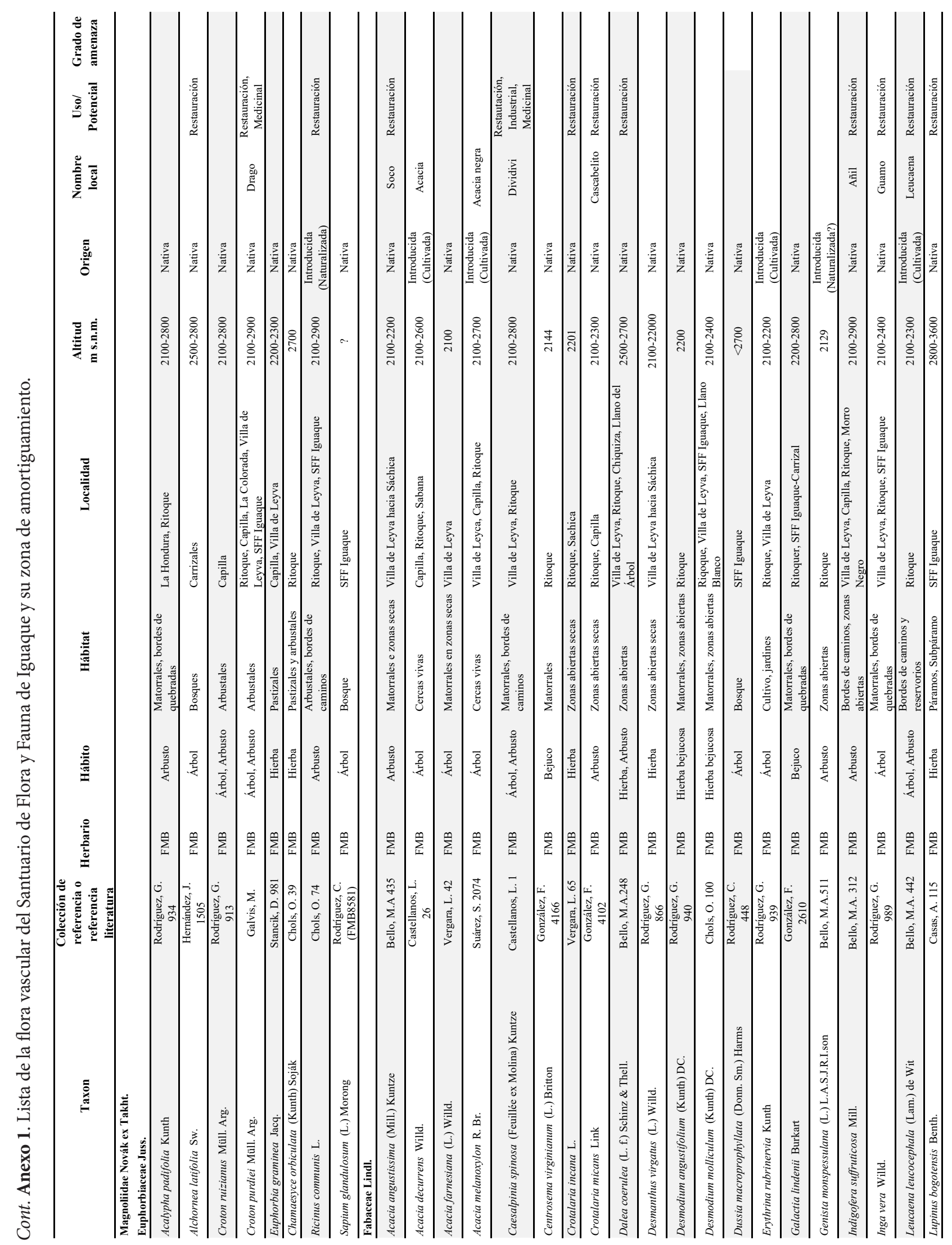




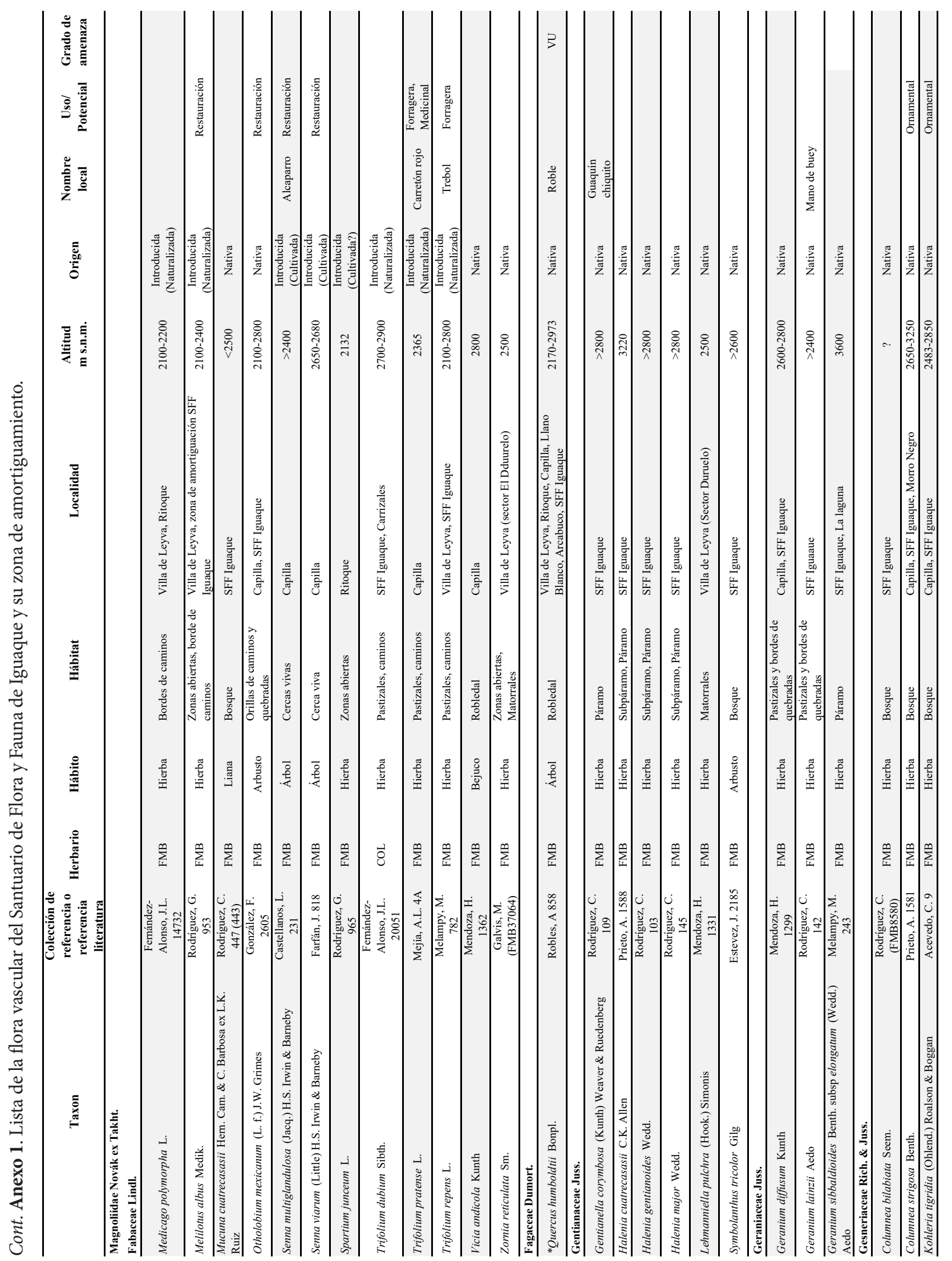




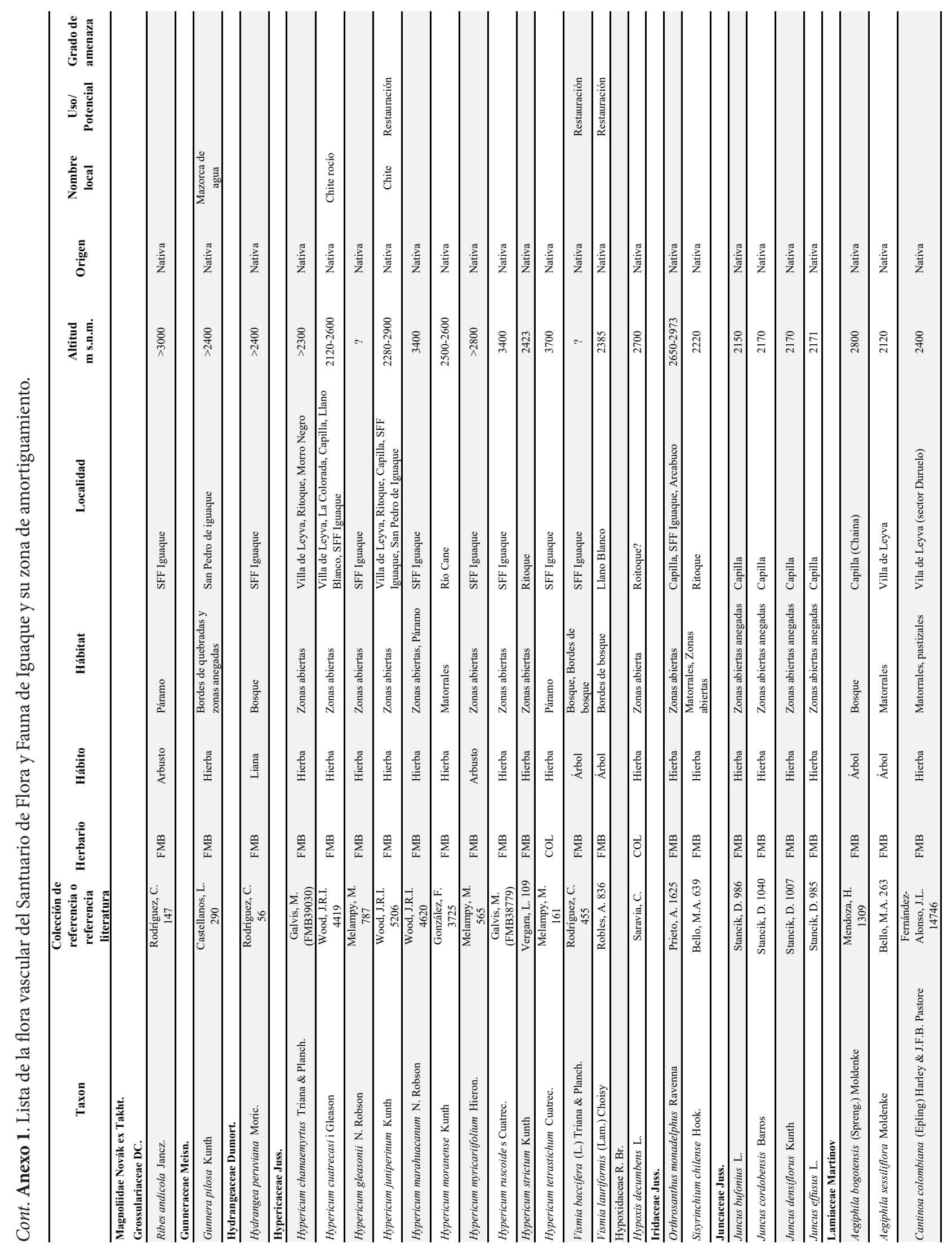




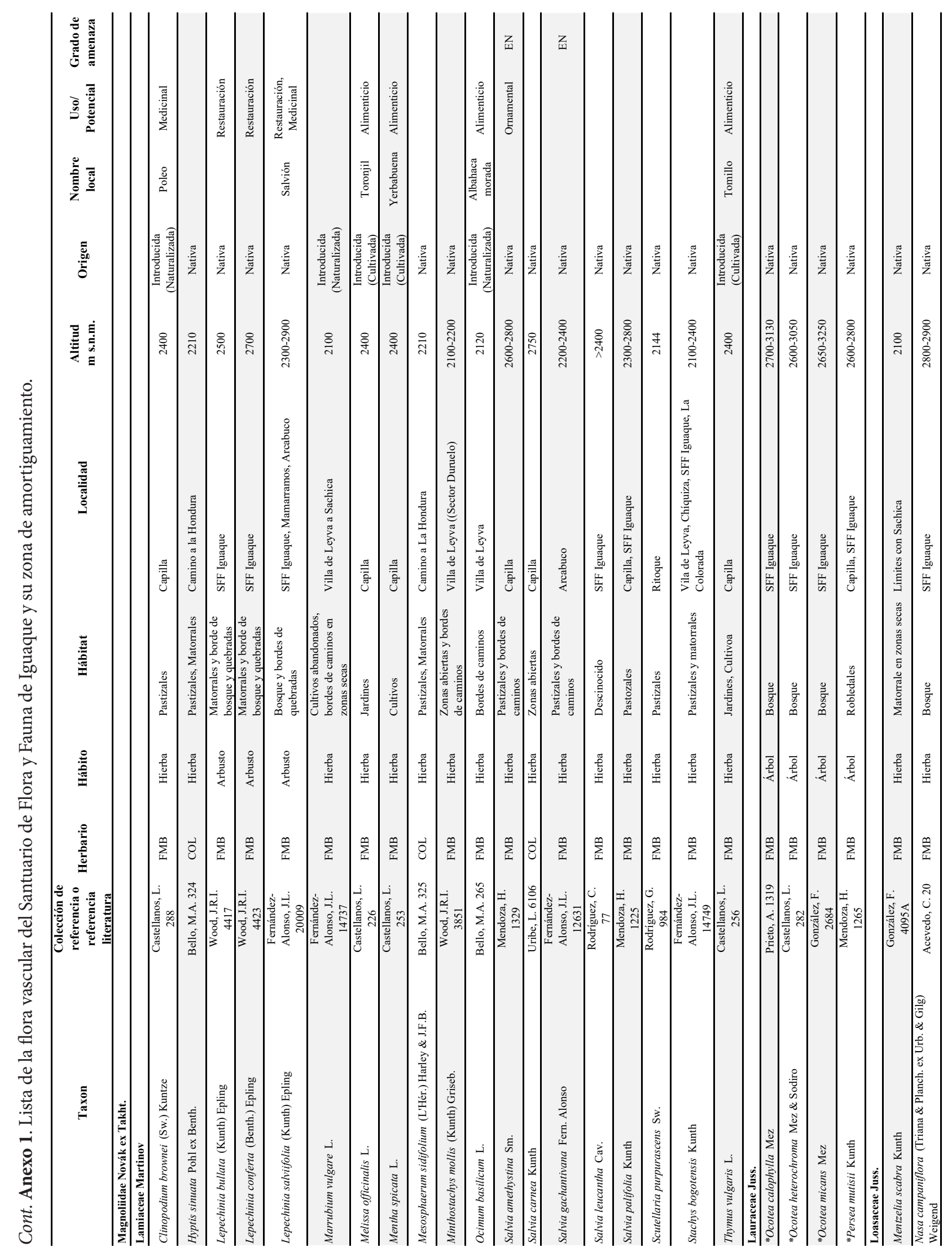




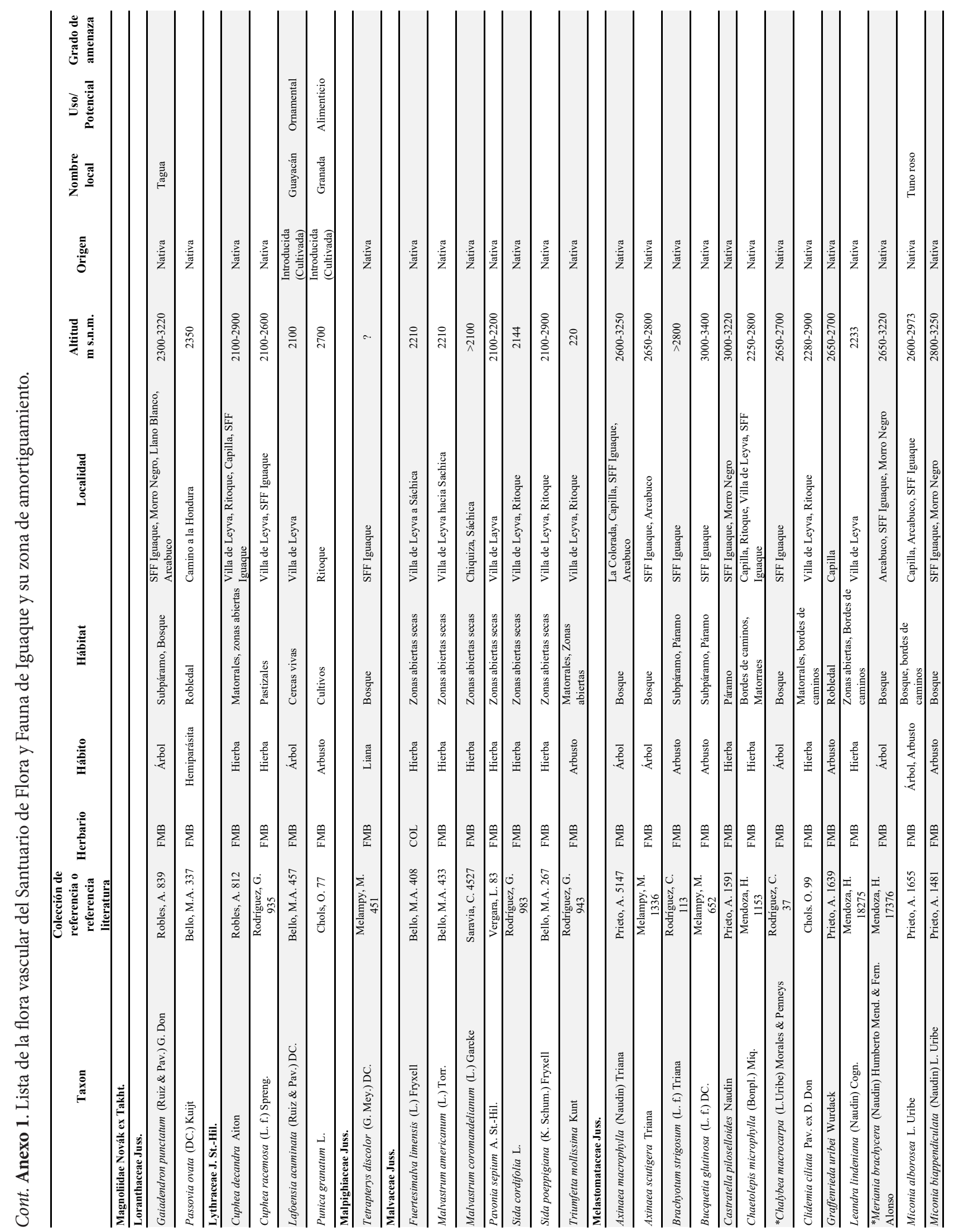







II

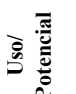

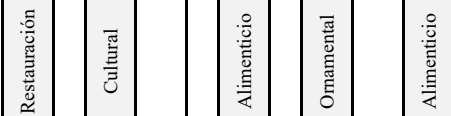

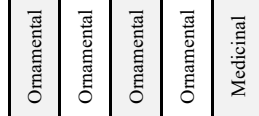

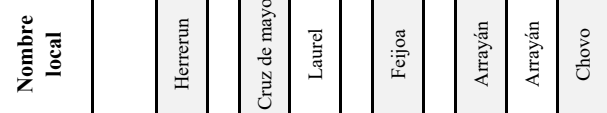

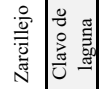

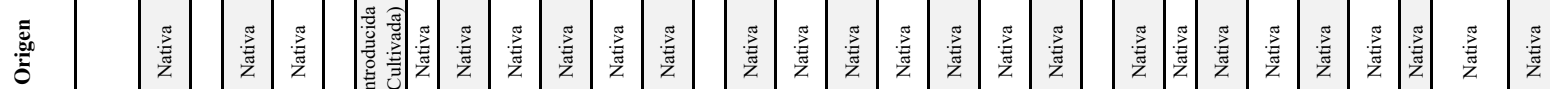



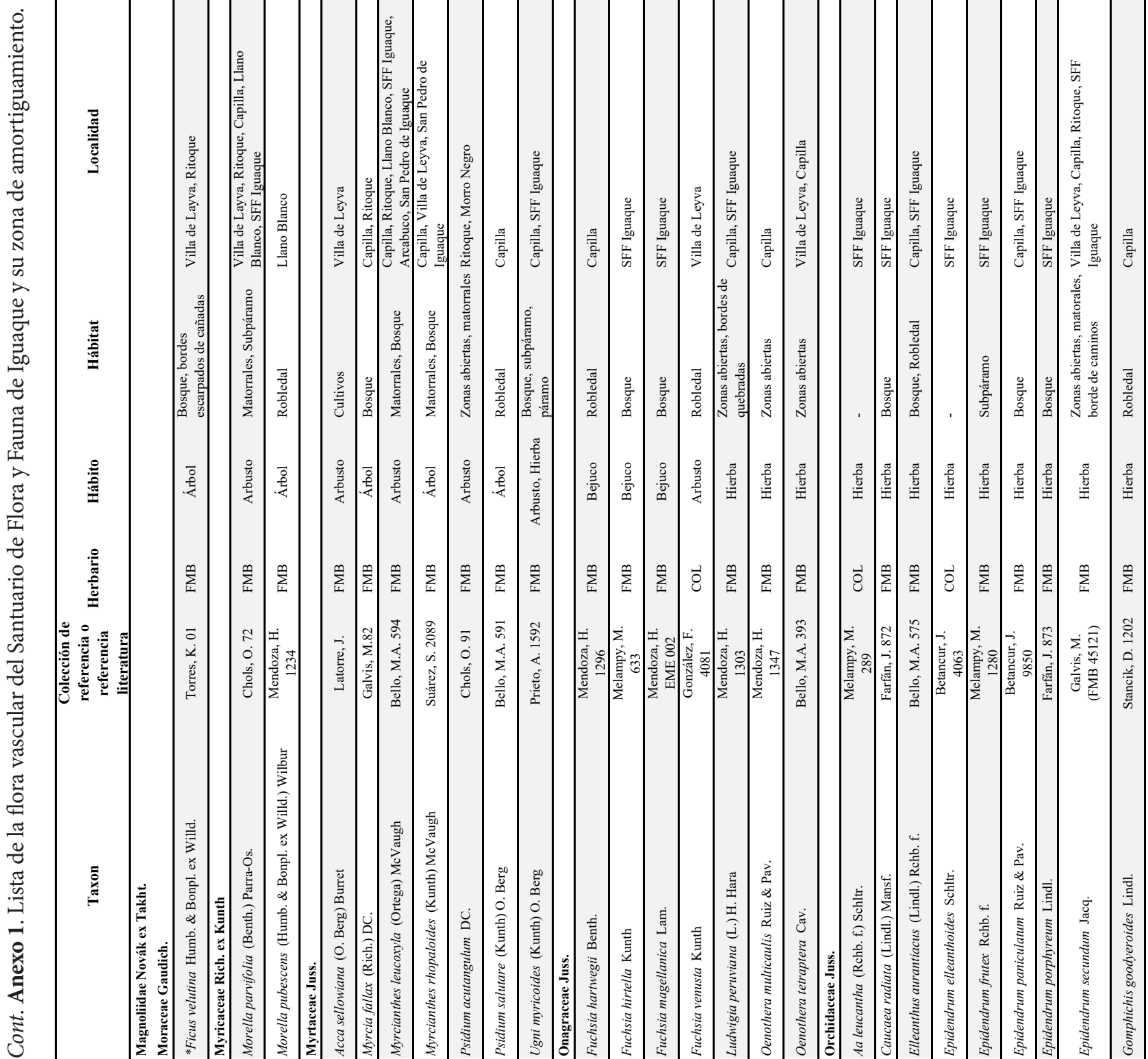




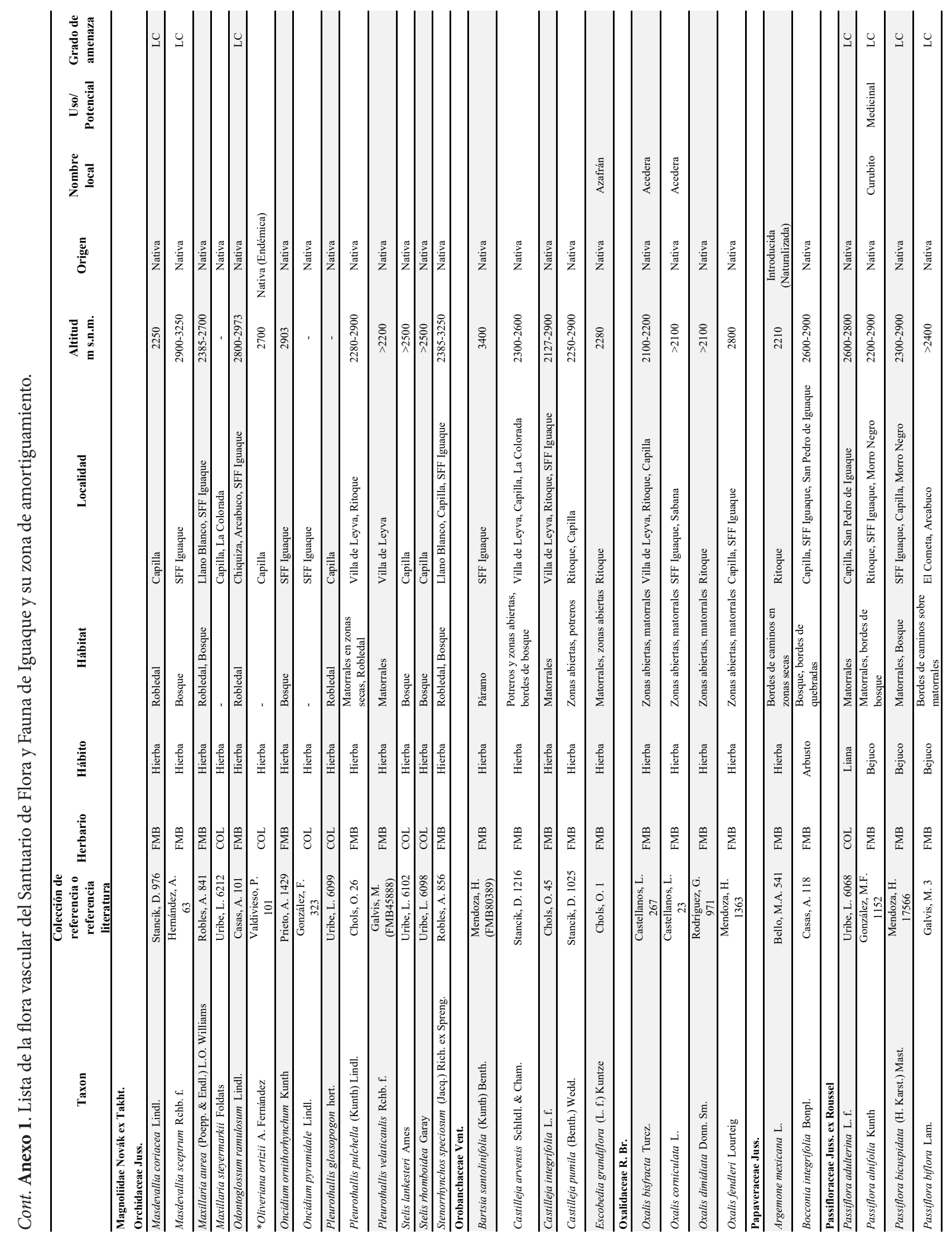




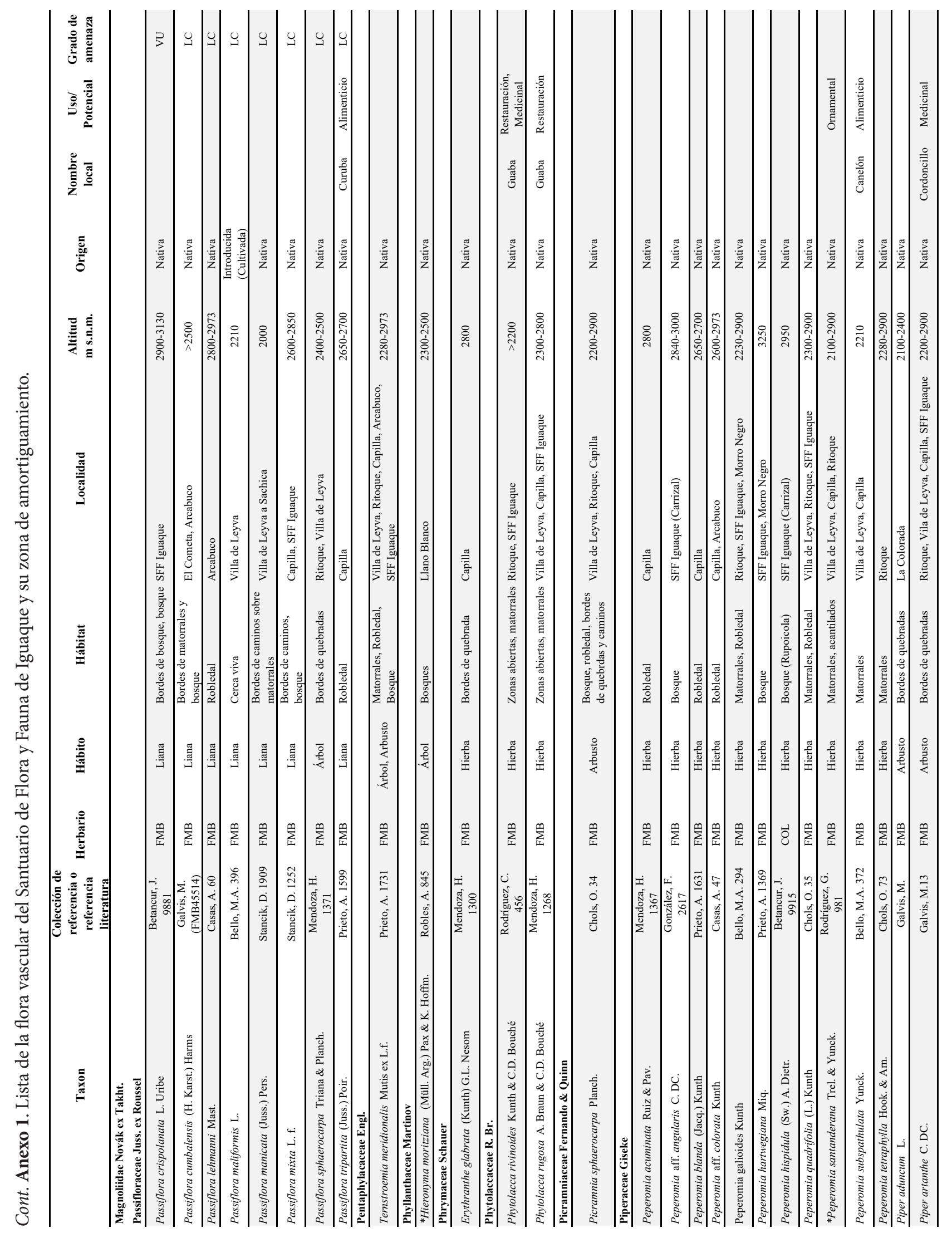




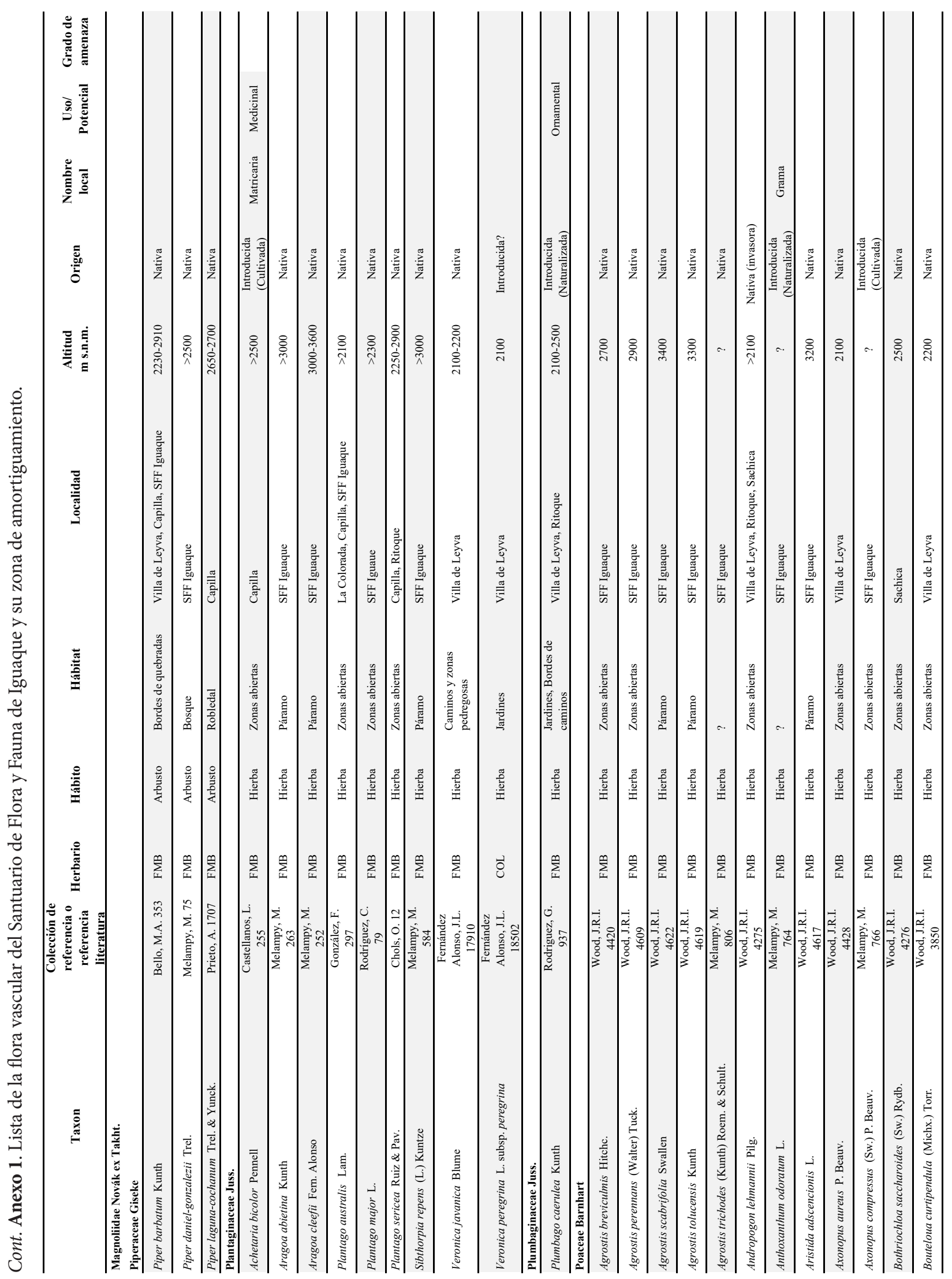




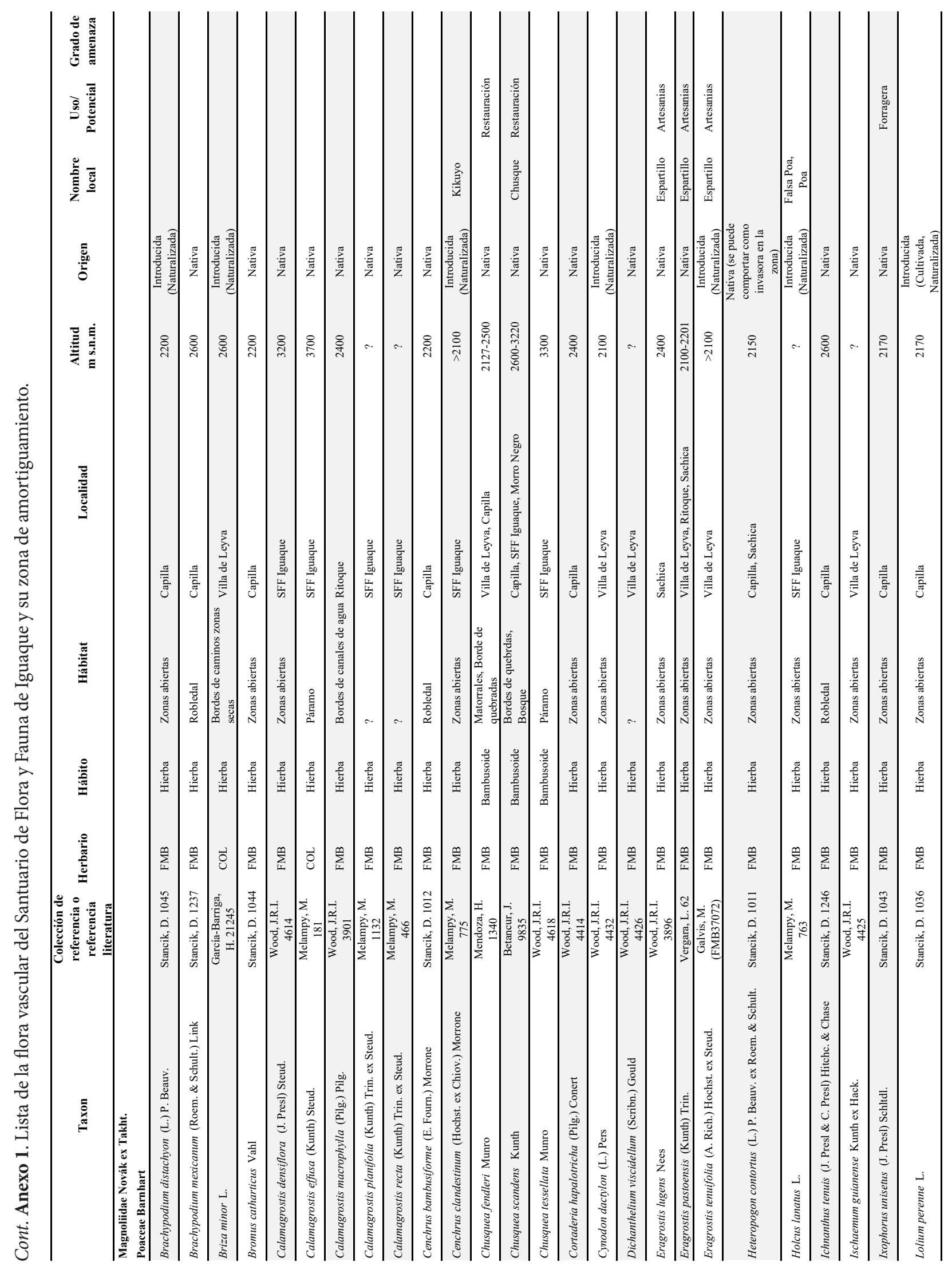




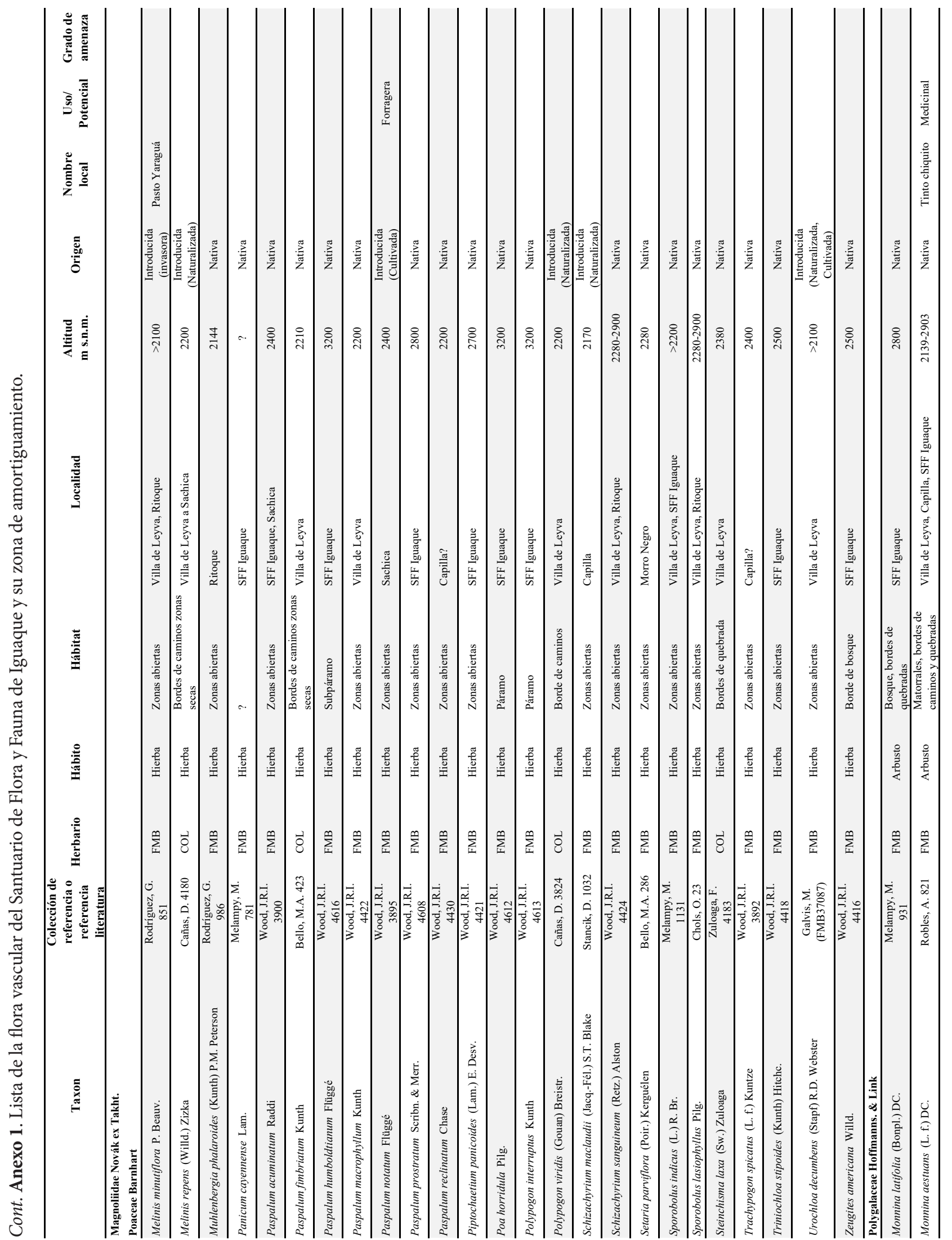




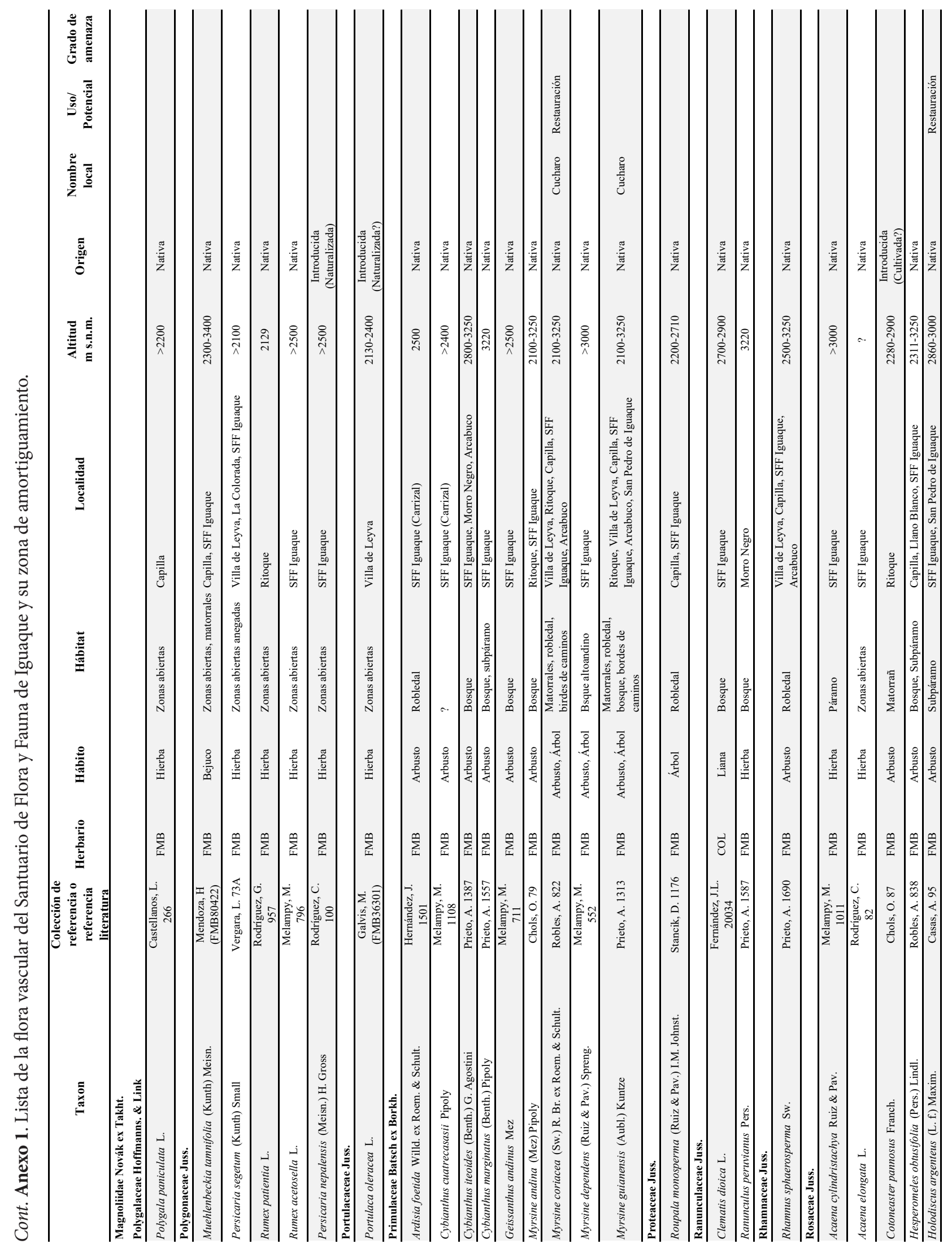




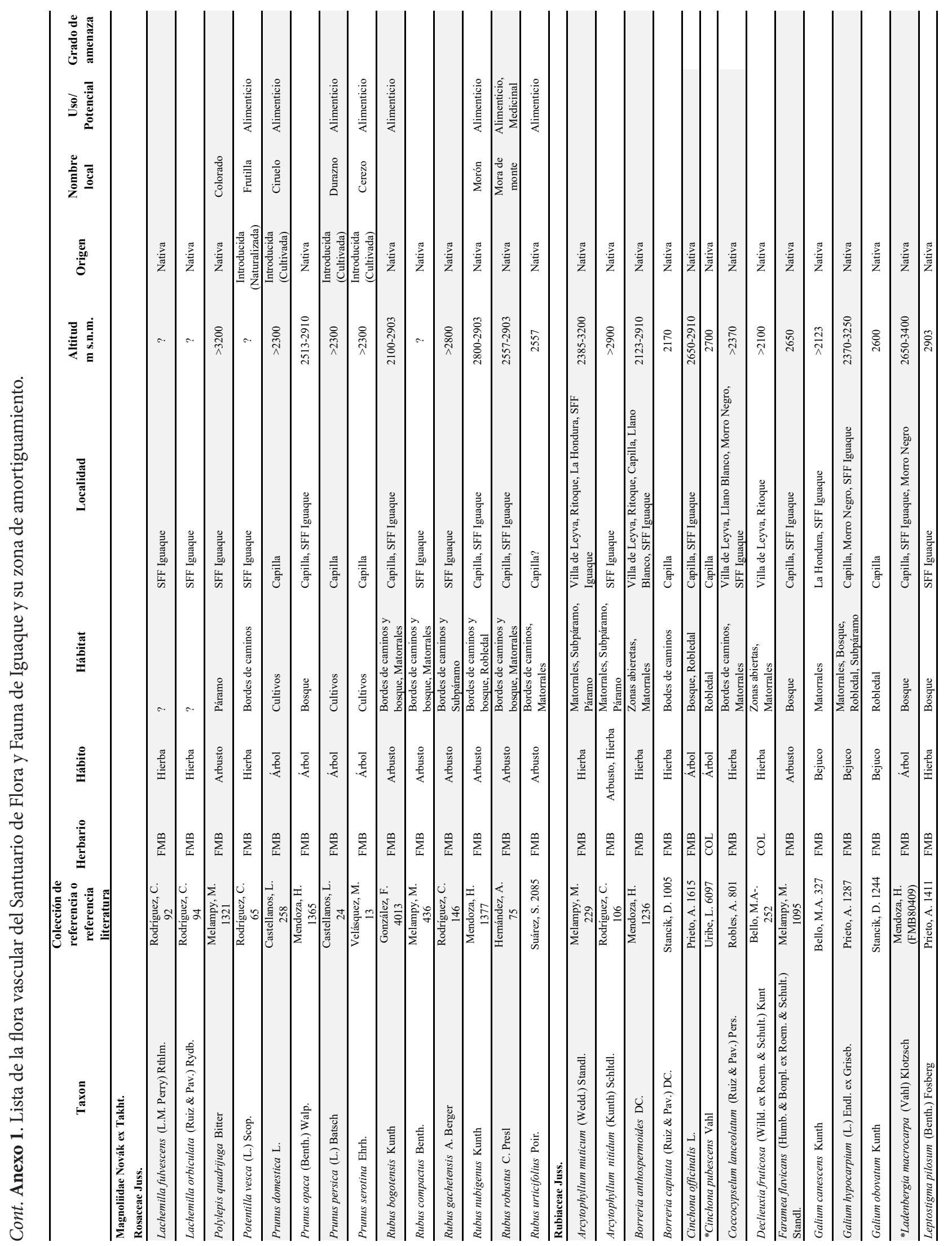









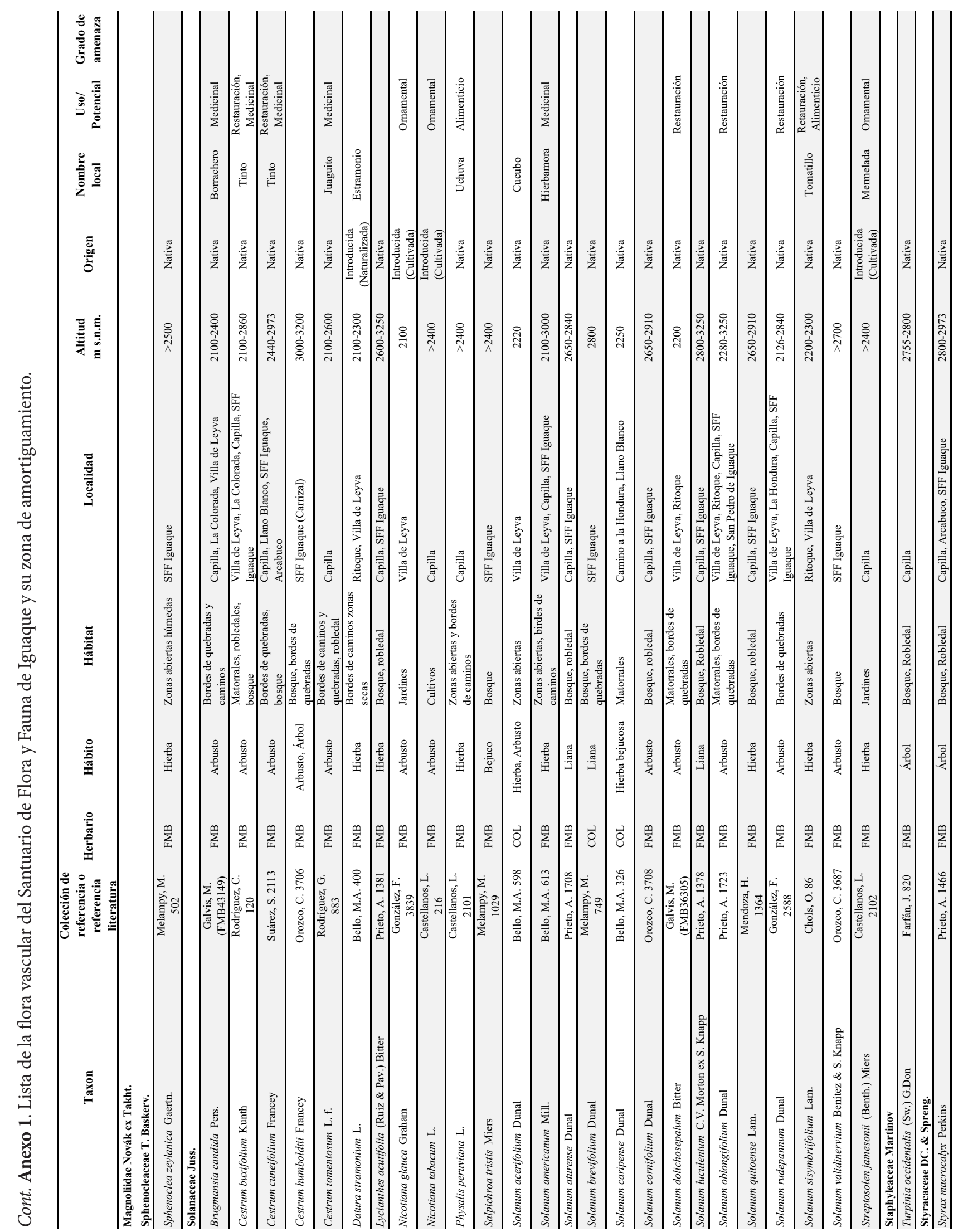




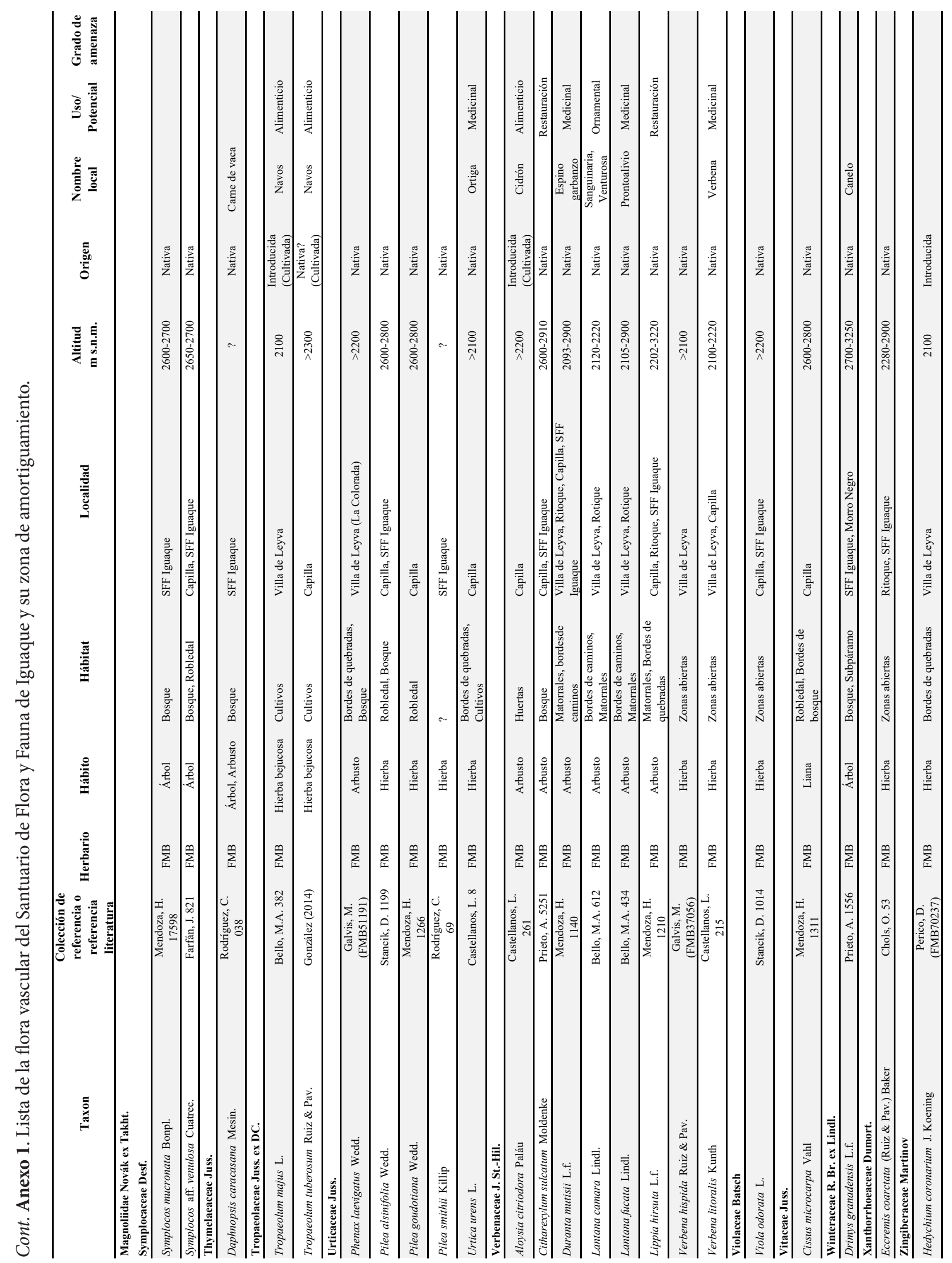




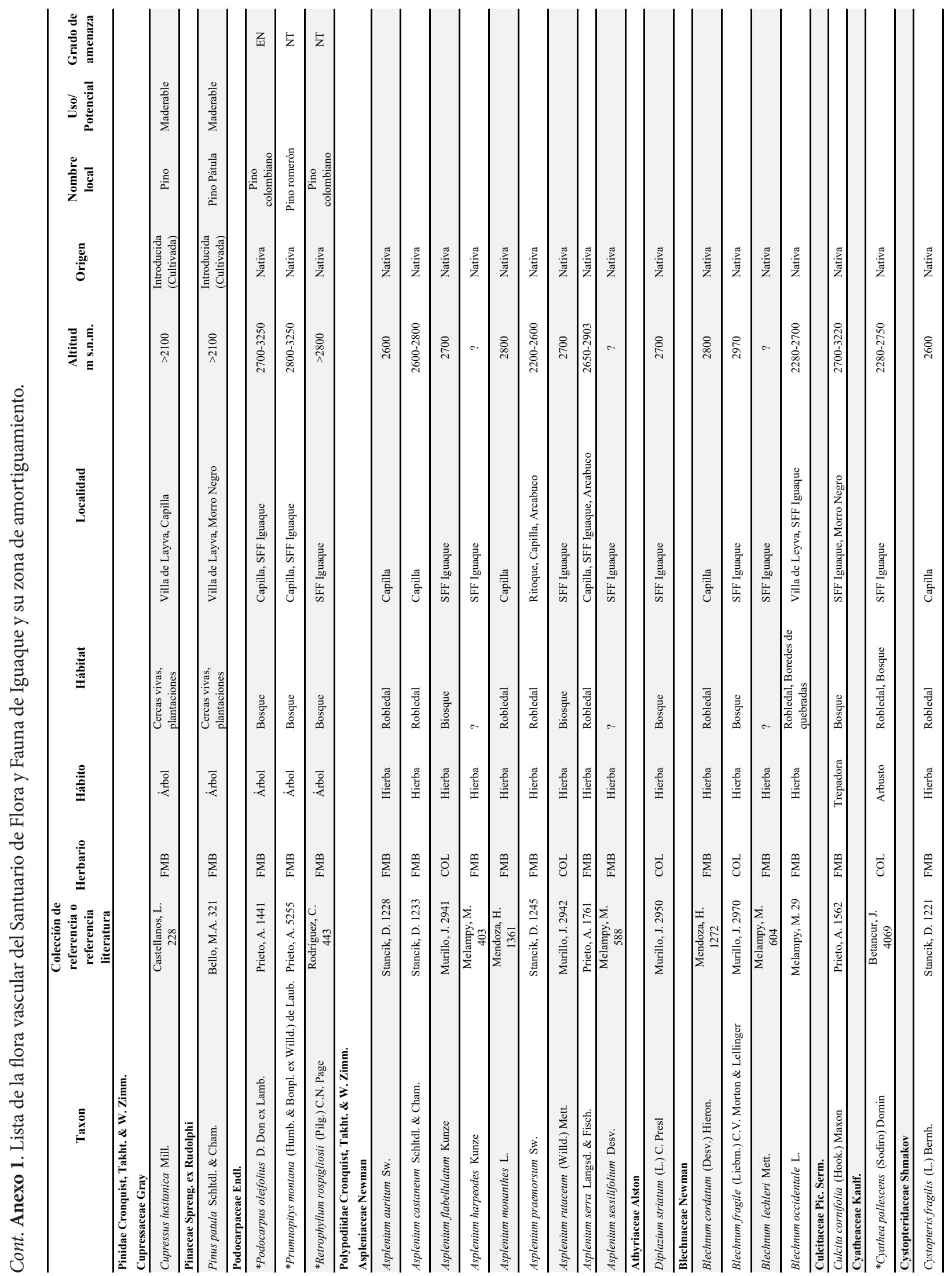




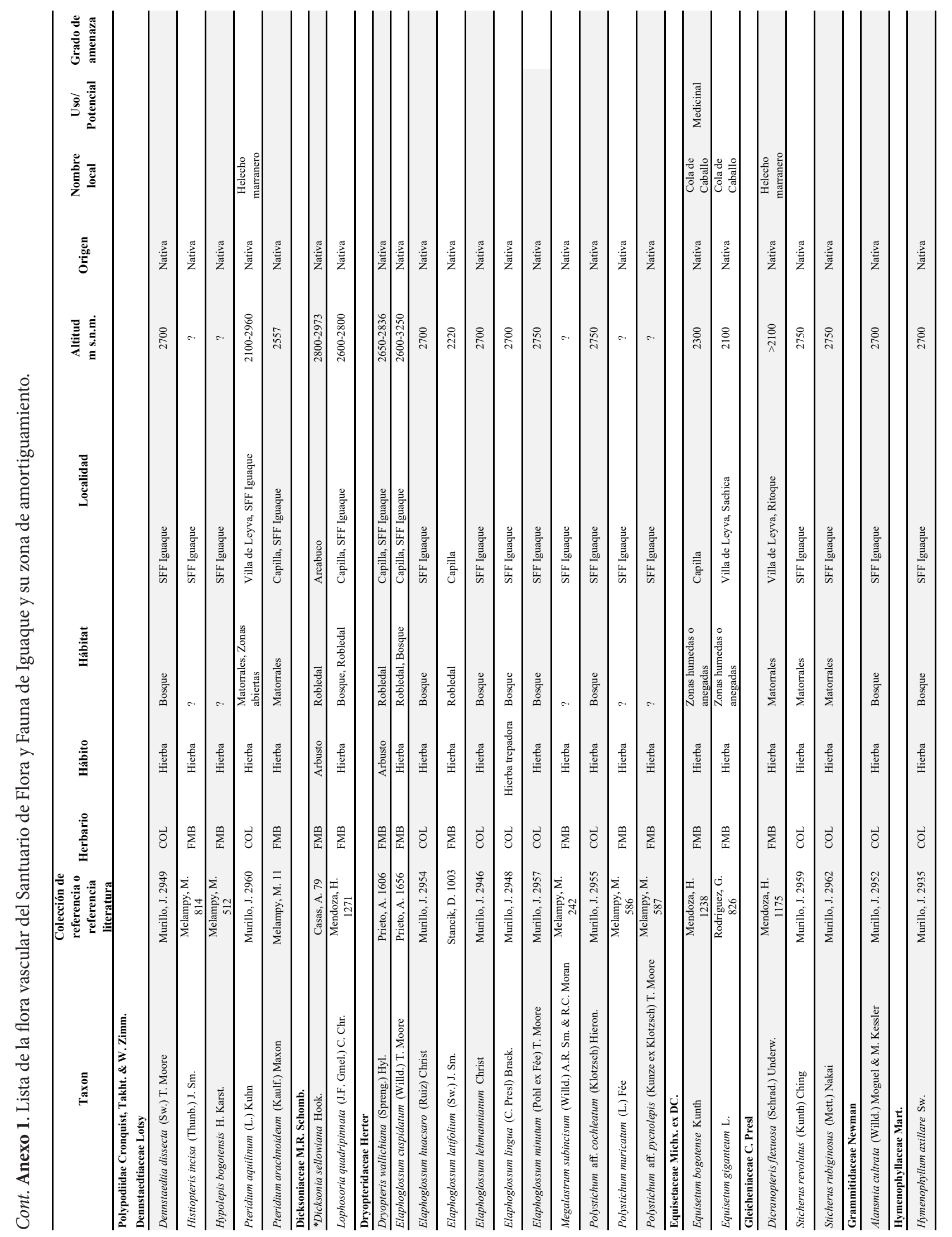




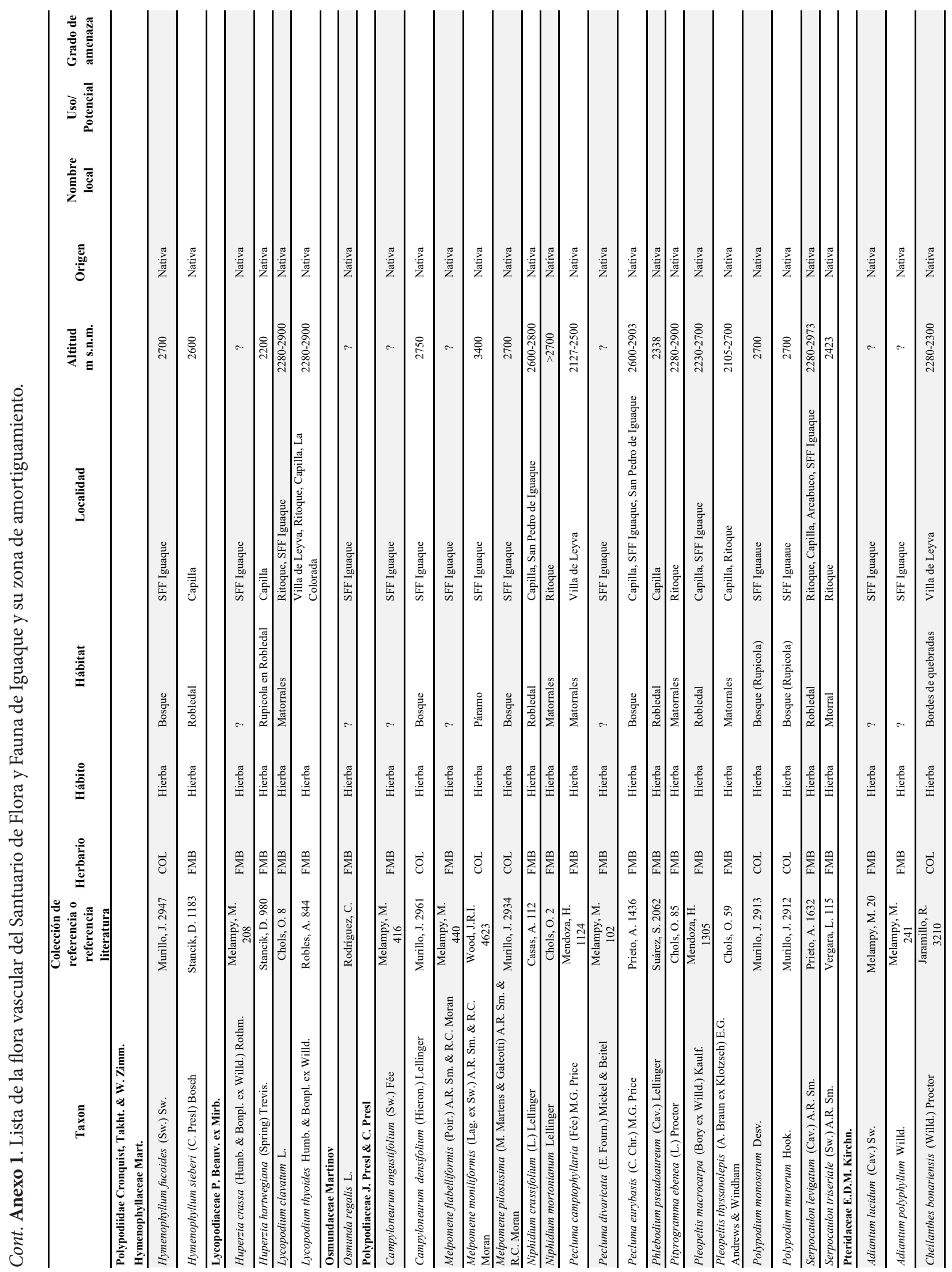




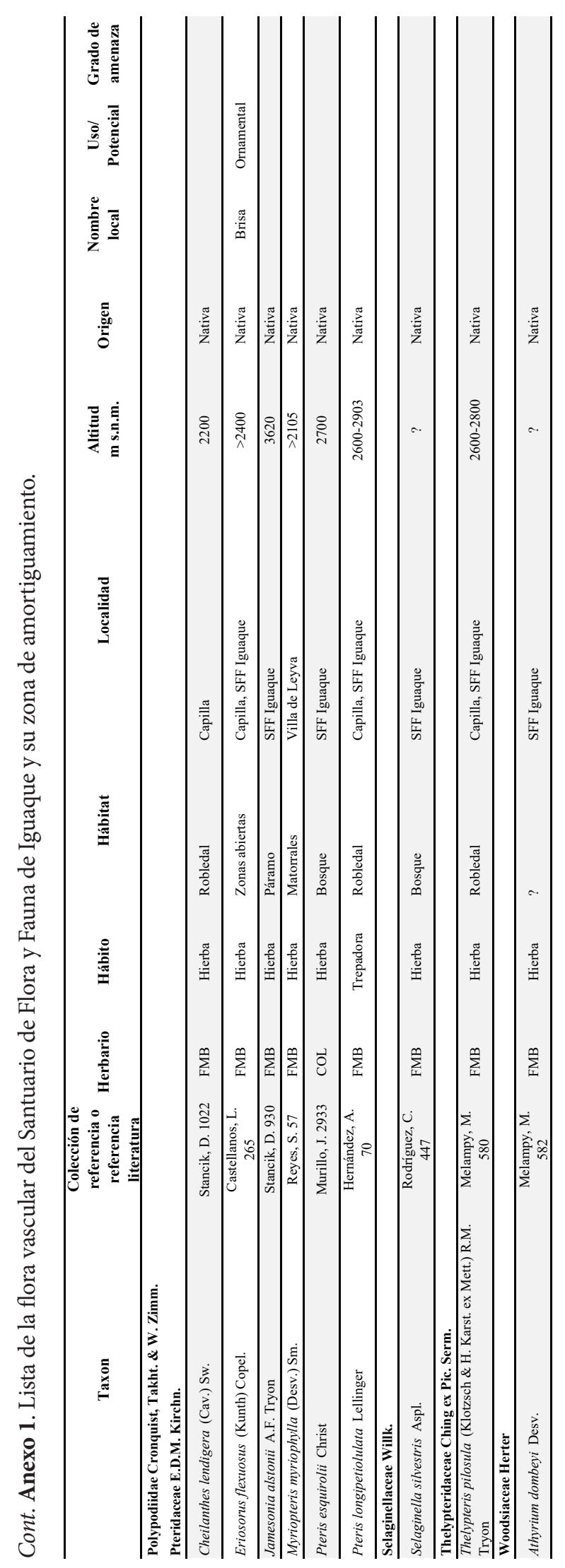

146 Biota Colombiana 18 (1) - 2017 


\section{Humberto Mendoza-Cifuentes}

Instituto de Investigación de Recursos Biológicos Alexander von Humboldt,

Claustro de San Agustín, Villa de Leyva,

Boyacá, Colombia

humendoza@humboldt.org.co
Catálogo de la flora vascular de los Parques Nacionales de Colombia: Santuario de Flora y Fauna de Iguaque y su zona de amortiguamiento

Citación del artículo: Mendoza-Cifuentes, H. 2017. Catálogo de la flora vascular de los Parques Nacionales de Colombia: Santuario de Flora y Fauna de Iguaque y su zona de amortiguamiento. Biota Colombiana 18 (1): 105-147 DOI: 10.21068/c2017.v18n01a8

Recibido: 20 de abril de 2016 


\section{Guía para autores}

(humboldt.org.co/es/bibliotecaypublicaciones/biota)

\section{Preparación del manuscrito}

El envío de un manuscrito implica la declaración explícita por parte del autor(es) de que este no ha sido previamente publicado, ni aceptado para su publicación en otra revista u otro órgano de difusión científica. Todas las contribuciones son de la entera responsabilidad de sus autores y no del Instituto de Investigación de Recursos Biológicos Alexander von Humboldt, ni de la revista o sus editores.

Los trabajos pueden estar escritos en español, inglés o portugués, y se recomienda que no excedan las 40 páginas (párrafo espaciado a 1,5 líneas) incluyendo tablas, figuras y anexos. En casos especiales el editor podrá considerar la publicación de trabajos más extensos, monografías o actas de congresos, talleres o simposios. De particular interés para la revista son las descripciones de especies nuevas para la ciencia, nuevos registros geográficos y listados de la biodiversidad regional.

Para la elaboración de los textos del manuscrito se puede usar cualquier procesador de palabras (preferiblemente Word); los listados (a manera de tabla) deben ser elaborados en una hoja de cálculo (preferiblemente Excel). Para someter un manuscrito es necesario además anexar una carta de intención en la que se indique claramente:

1. Nombre completo del (los) autor (es), y direcciones para envío de correspondencia (es indispensable suministrar una dirección de correo electrónico para comunicación directa).

\section{Título completo del manuscrito.}

3. Nombres, tamaños y tipos de archivos suministrados.

4. Lista mínimo de tres revisores sugeridos que puedan evaluar el manuscrito, con sus respectivas direcciones electrónicas.

\section{Evaluación del manuscrito}

Los manuscritos sometidos serán revisados por pares científicos calificados, cuya respuesta final de evaluación puede ser: a) aceptado (en cuyo caso se asume que no existe ningún cambio, omisión o adición al artículo, y que se recomienda su publicación en la forma actualmente presentada); b) aceptación condicional (se acepta y recomienda el artículo para su publicación solo si se realizan los cambios indicados por el evaluador); y c) rechazo (cuando el evaluador considera que los contenidos o forma de presentación del artículo no se ajustan a los requerimientos y estándares de calidad de Biota Colombiana).

\section{Texto}

- Para la presentación del manuscrito configure las páginas de la siguiente manera: hoja tamaño carta, márgenes de $2,5 \mathrm{~cm}$ en todos los lados, interlineado 1,5 y alineación hacia la izquierda (incluyendo título y bibliografía).

- Todas las páginas de texto (a excepción de la primera correspondiente al título), deben numerarse en la parte inferior derecha de la hoja.
- Use letra Times New Roman o Arial, tamaño 12 puntos en todos los textos. Máximo 40 páginas, incluyendo tablas, figuras y anexos. Para tablas cambie el tamaño de la fuente a 10 puntos. Evite el uso de negritas o subrayados.

- Los manuscritos debe llevar el siguiente orden: título, resumen y palabras clave, abstract y key words, introducción, material y métodos, resultados, discusión, conclusiones (optativo), agradecimientos (optativo) y bibliografía. Seguidamente, presente una página con la lista de tablas, figuras y anexos. Finalmente, incluya las tablas, figuras y anexos en archivos separadas, debidamente identificadas.

- Escriba los nombres científicos de géneros, especies y subespecies en cursiva (itálica). Proceda de la misma forma con los términos en latín (p. e. sensu, et al.). No subraye ninguna otra palabra o título. No utilice notas al pie de página.

- En cuanto a las abreviaturas y sistema métrico decimal, utilice las normas del Sistema Internacional de Unidades (SI) recordando que siempre se debe dejar un espacio libre entre el valor numérico y la unidad de medida (p. e. $16 \mathrm{~km}, 23^{\circ} \mathrm{C}$ ). Para medidas relativas como m/seg., use m.seg ${ }^{-1}$.

- Escriba los números del uno al diez siempre con letras, excepto cuando preceden a una unidad de medida (p. e. $9 \mathrm{~cm}$ ) o si se utilizan como marcadores (p. e. parcela 2, muestra 7).

- No utilice punto para separar los millares, millones, etc. Utilice la coma para separar en la cifra la parte entera de la decimal (p. e. 3,1416). Enumere las horas del día de 0:00 a 24:00.

- Exprese los años con todas las cifras sin demarcadores de miles (p. e. 1996-1998). En español los nombres de los meses y días (enero, julio, sábado, lunes) siempre se escriben con la primera letra minúscula, no así en inglés.

- Los puntos cardinales (norte, sur, este y oeste) siempre deben ser escritos en minúscula, a excepción de sus abreviaturas $\mathrm{N}, \mathrm{S}$, $\mathrm{E}, \mathrm{O}$ (en inglés W), etc. La indicación correcta de coordenadas geográficas es como sigue: $02^{\circ} 37^{\prime} 53^{\prime \prime} \mathrm{N}-56^{\circ} 28^{\prime} 53^{\prime \prime} \mathrm{O}$. La altitud geográfica se citará como se expresa a continuación: 1180 m s.n.m. (en inglés $1180 \mathrm{~m}$ a.s.l).

- Las abreviaturas se explican únicamente la primera vez que son usadas.

- Al citar las referencias en el texto mencione los apellidos de los autores en caso de que sean uno o dos, y el apellido del primero seguido por et al. cuando sean tres o más. Si menciona varias referencias, éstas deben ser ordenadas cronológicamente y separadas por comas (p. e. Rojas 1978, Bailey et al. 1983, Sephton 2001, 2001).

- Resumen: incluya un resumen de máximo 200 palabras, tanto en español o portugués como inglés.

- Palabras Clave: máximo seis palabras clave, preferiblemente complementarias al título del artículo, en español e inglés. 


\section{Agradecimientos}

Opcional. Párrafo sencillo y conciso entre el texto y la bibliografía. Evite títulos como Dr., Lic., TSU, etc.

\section{Fotografías, figuras, tablas y anexos}

Refiera las figuras (gráficas, diagramas, ilustraciones y fotografías) sin abreviación (p. e. Figura 3) al igual que las tablas (p. e. Tabla 1). Gráficos (p. e. CPUE anuales) y figuras (histogramas de tallas), preferiblemente en blanco y negro, con tipo y tamaño de letra uniforme. Deben ser nítidas y de buena calidad, evitando complejidades innecesarias (por ejemplo, tridimensionalidad en gráficos de barras); cuando sea posible use solo colores sólidos en lugar de tramas. Las letras, números o símbolos de las figuras deben ser de un tamaño adecuado de manera que sean claramente legibles una vez reducidas. Para el caso de las fotografías y figuras digitales es necesario que estas sean guardadas como formato tiff con una resolución de 300 dpi. Es oportuno que indique en qué parte del texto desea insertarla.

Lo mismo aplica para las tablas y anexos, los cuales deben ser simples en su estructura (marcos) y estar unificados. Presente las tablas en archivo aparte (Excel), identificadas con su respectivo número. Haga las llamadas a pie de página de tabla con letras ubicadas como superíndice. Evite tablas grandes sobrecargadas de información y líneas divisorias o presentadas en forma compleja. Es oportuno que indique en qué parte del texto desea insertar tablas y anexos.

\section{Bibliografía}

Contiene únicamente la lista de las referencias citadas en el texto. Ordénelas alfabéticamente por autores y cronológicamente para un mismo autor. Si hay varias referencias de un mismo autor(es) en el mismo año, añada las letras a, b, c, etc. No abrevie los nombres de las revistas. Presente las referencias en el formato anexo, incluyendo el uso de espacios, comas, puntos, mayúsculas, etc.

\section{Artículo EN REVISTAS}

Agosti, D., C. R. Brandao y S. Diniz. 1999. The new world species of the subfamily Leptanilloidinae (Hymenoptera: Formicidae). Systematic Entomology 24: 14-20.

\section{LIBROS, TESIS E INFORMES TÉCNICOS}

Libros: Gutiérrez, F. P. 2010. Los recursos hidrobiológicos y pesqueros en Colombia. Instituto de Investigación de Recursos Biológicos Alexander von Humboldt. Bogotá, D. C., 118 pp.

Tesis: Cipamocha, C. A. 2002. Caracterización de especies y evaluación trófica de la subienda de peces en el raudal Chorro de Córdoba, bajo río Caquetá, Amazonas, Colombia. Trabajo de grado. Universidad Nacional de Colombia, Facultad de Ciencias, Departamento de Biología. Bogotá D. C., 160 pp.

Informes técnicos: Andrade, G. I. 2010. Gestión del conocimiento para la gestión de la biodiversidad: bases conceptuales y propuesta programática para la reingeniería del Instituto Humboldt. Informe Técnico. Instituto de Investigación de Recursos Biológicos Alexander von Humboldt. Bogotá D. C., 80 pp.

Capítulo en libro o en informe: Fernández F., E. E. Palacio y W. P. MacKay. 1996. Introducción al estudio de las hormigas (Hymenoptera: Formicidae) de Colombia. Pp:349-412. En: Amat, G. D., G. Andrade y F. Fernández (Eds.). Insectos de Colombia. Estudios Escogidos. Academia Colombiana de Ciencias Exactas, Físicas y Naturales \& Centro Editorial Javeriano, Bogotá.

Resumen en congreso, simposio, talleres: Señaris, J. C. 2001. Distribución geográfica y utilización del hábitat de las ranas de cristal (Anura; Centrolenidae) en Venezuela. En: Programa y Libro de Resúmenes del IV Congreso Venezolano de Ecología. Mérida, Venezuela, p. 124.

PÁginas Web

No serán incluidas en la bibliografía, sino que se señalarán claramente en el texto al momento de mencionarlas.

\title{
Guidelines for authors
}

\author{
(humboldt.org.co/es/bibliotecaypublicaciones/biota)
}

\section{Manuscript preparation}

Submitting a manuscript implies the explicit statement by the author(s) that the paper has not been published before nor accepted for publication in another journal or other means of scientific diffusion. Contributions are entire responsibility of the author and not the Alexander von Humboldt Institute for Research on Biological Resources, or the journal and their editors.

Papers can be written in Spanish, English or Portuguese and it is recommended not exceeding 40 pages (with paragraphs spaced at 1,5) including tables, figures and Annex. For special cases, the editor could consider publishing more extensive papers, monographs or symposium conclusions. New species descriptions for science, new geographic records and regional biodiversity lists are of particular interest for this journal.
Any word-processor program may be used for the text (Word is recommended). taxonomic list or any other type of table, should be prepared in spreadsheet aplication (Excel is recommended). To submit a manuscript must be accompanied by a cover letter which clearly indicate $\mathrm{s}$ :

1. Full names, mailing addresses and e-mail addresses of all authors. (Please note that email addresses are essential to direct communication).

2. The complete title of the article.

3. Names, sizes, and types of files provide.

4. A list of the names and addresses of at least three (3) reviewers who are qualified to evaluate the manuscript. 


\section{Evaluation}

Submitted manuscript will have a peer review evaluation. Resulting in any of the following: a) accepted (in this case we assume that no change, omission or addition to the article is required and it will be published as presented.); b) conditional acceptance (the article is accepted and recommended to be published but it needs to be corrected as indicated by the reviewer); and c) rejected (when the reviewer considers that the contents and/or form of the paper are not in accordance with requirements of publication standards of Biota Colombiana).

\section{Text}

- The manuscript specifications should be the following: standard letter size paper, with $2.5 \mathrm{~cm}$ margins on all sides, 1.5-spaced and left-aligned (including title and bibliography).

- All text pages (with the exception of the title page) should be numbered. Pages should be numbered in the lower right corner.

- Use Times New Roman or Arial font, size 12, for all texts. Use size 10 text in tables. Avoid the use of bold or underlining. 40 pages maximum, including tables, figures and annex. For tables use size 10 Times New Roman or Arial Font (the one used earlier).

- The manuscripts must be completed with the following order: title, abstract and key words, then in Spanish Título, Resumen y Palabras claves. Introduction, Materials and Methods, Results, Discussion, conclusions (optional), acknowledgements (optional) and bibliography. Following include a page with the Table, Figure and Annex list. Finally tables, figures and annex should be presented and clearly identified in separate tables.

- Scientific names of genera, species and subspecies should be written in italic. The same goes for Latin technical terms (i.e sensu, et al.). Avoid the use of underlining any word or title. Do not use footnotes.

- As for abbreviations and the metric system, use the standards of the International System of Units (SI) remembering that there should always be a space between the numeric value and the measure unit (e.g., $16 \mathrm{~km}, 23{ }^{\circ} \mathrm{C}$ ). For relative measures such as $\mathrm{m} / \mathrm{sec}$, use $\mathrm{m} \cdot \mathrm{sec}^{-1}$.

- Write out numbers between one to ten in letters except when it precedes a measure unit (e.g., $9 \mathrm{~cm}$ ) or if it is used as a marker (e.g., lot 9, sample 7).

- Do not use a point to seperate thousands, millions, etc. Use a comma to separate the whole part of the decimal (e.g., 3,1416). Numerate the hours of the from 0:00 to 24:00. Express years with all numbers and without marking thousands (e.g., 19961998). In Spanish, the names of the months and days (enero, julio, sábado, lunes) are always written with the first letter as a lower case, but it is not this way in English.

- The cardinal points (north, south, east, and west) should always be written in lower case, with the excpetino of abbreviations $\mathrm{N}, \mathrm{S}, \mathrm{E}, \mathrm{O}$ (in English NW), etc. The correct indication of geographic coordinates is as follows: $02^{\circ} 37^{\prime} 53^{\prime \prime} \mathrm{N}-56^{\circ} 28^{\prime} 53^{\prime \prime} \mathrm{O}$. The geographic altitude should be cited as follows: $1180 \mathrm{~m}$ a.s.l.

- Abbreviations are explained only the first time they are used.
- When quoting references in the text mentioned author's last names when they are one or two, and et al. after the last name of the first author when there are three or more. If you mention many references, they should be in chronological order and separated by commas (e.g., Rojas 1978, Bailey et al. 1983, Sephton 2001, 2001).

- ABSTRACT: include an abstract of 200 words maximum, in Spanish, Portuguese or English.

- KeY WORDS: six key words maximum, complementary to the title.

\section{Pictures, Figures, Tables and Annex}

- Figures (graphics, diagrams, illustrations and photographs) without abbreviation (e.g. Figure 3) the same as tables (e.g., Table 1). Graphics and figures should be in black and white, with uniform font type and size. They should be sharp and of good quality, avoiding unnecessary complexities (e.g., three dimensions graphics). When possible use solid color instead of other schemes. The words, numbers or symbols of figures should be of an adequate size so they are readable once reduced. Digital figures must be sent at 300 dpi and in .tiff format. Please indicate in which part of the text you would like to include it.

- The same applies to tables and annexes, which should be simple in structure (frames) and be unified. Present tables in a separate file (Excel), identified with their respective number. Make calls to table footnotes with superscript letters above. Avoid large tables of information overload and fault lines or presented in a complex way. It is appropriate to indicate where in the text to insert tables and annexes.

\section{Bibliography}

References in bibliography contains only the list of references cited in the text. Sort them alphabetically by authors and chronologically by the same author. If there are several references by the same author(s) in the same year, add letters a, b, c, etc. Do not abbreviate journal names. Present references in the attached format, including the use of spaces, commas, periodss, capital letters, etc.

\section{JOURNAL ARTICLE}

Agosti, D., C. R. Brandao y S. Diniz. 1999. The new world species of the subfamily Leptanilloidinae (Hymenoptera: Formicidae). Systematic Entomology 24: 14-20.

\section{BOOK, THESIS, TECHNICAL REVIEWS}

Book: Gutiérrez, F. P. 2010. Los recursos hidrobiológicos y pesqueros en Colombia. Instituto de Investigación de Recursos Biológicos Alexander von Humboldt. Bogotá, D. C. 118 pp.

Thesis: Cipamocha, C. A. 2002. Caracterización de especies y evaluación trófica de la subienda de peces en el raudal Chorro de Córdoba, bajo río Caquetá, Amazonas, Colombia. Trabajo de grado. Universidad Nacional de Colombia, Facultad de Ciencias, Departamento de Biología. Bogotá D. C. 160 pp.

Technical reviews: Andrade, G. I. 2010. Gestión del conocimiento para la gestión de la biodiversidad: bases conceptuales y propuesta programática para la reingeniería del Instituto Humboldt. Informe 
Técnico. Instituto de Investigación de Recursos Biológicos Alexander von Humboldt. Bogotá D. C. 80 pp.

Book chapter or in review: Fernández F., E. E. Palacio y W. P. MacKay. 1996. Introducción al estudio de las hormigas (Hymenoptera: Formicidae) de Colombia. Pp: 349-412. En: Amat, G. D., G. Andrade y F. Fernández (Eds.). Insectos de Colombia. Estudios Escogidos. Academia Colombiana de Ciencias Exactas, Físicas y Naturales \& Centro Editorial Javeriano, Bogotá.
Symposium abstract: Señaris, J. C. 2001. Distribución geográfica y utilización del hábitat de las ranas de cristal (Anura; Centrolenidae) en Venezuela. En: Programa y Libro de Resúmenes del IV Congreso Venezolano de Ecología. Mérida, Venezuela, p. 124.

WeB PAGES

Not be included in the literature, but clearly identified in the text at the time of mention.

\section{Guía para autores - Artículos de Datos}

www.humboldt.org.co/es/bibliotecaypublicaciones/biota- biotacol@humboldt.org.co www.sibcolombia.net - sib+iac@humboldt.org.co

El objetivo de esta guía es establecer y explicar los pasos necesarios para la elaboración de un manuscrito con el potencial de convertirse en artículo de datos para ser publicado en la revista Biota Colombiana. En esta guía se incluyen aspectos relacionados con la preparación de datos y el manuscrito.

\section{¿Qué es un artículo de datos?}

Un artículo de datos o Data Paper es un tipo de publicación académica que ha surgido como mecanismo para incentivar la publicación de datos sobre biodiversidad, a la vez que es un medio para generar reconocimiento académico y profesional adecuado a todas las personas que intervienen de una manera u otra en la gestión de información sobre biodiversidad.

Los artículos de datos contienen las secciones básicas de un artículo científico tradicional. Sin embargo, estas se estructuran de acuerdo a un estándar internacional para metadatos (información que le da contexto a los datos) conocido como el GBIF Metadata Profile (GMP) ${ }^{1}$. La estructuración del manuscrito con base en este estándar se da, en primer lugar, para facilitar que la comunidad de autores que publican conjuntos de datos a nivel global, con presencia en redes como la Global Biodiversity Information Facility (GBIF) y otras redes relacionadas, puedan publicar fácilmente artículos de datos obteniendo el reconocimiento adecuado a su labor. En segundo lugar, para estimular que los autores de este tipo de conjuntos de datos que aún no han publicado en estas redes de información global, tengan los estímulos necesarios para hacerlo.

Un artículo de datos debe describir de la mejor manera posible el quién, qué, dónde, cuándo, por qué y cómo de la toma y almacenamiento de los datos, sin llegar a convertirse en el medio para realizar un análisis exhaustivo de los mismos, como sucede en otro tipo de publicaciones académicas. Para profundizar en este modelo de publicación se recomienda consultar a Chavan y Penev $(2011)^{2}$.

\section{¿Qué manuscritos pueden llegar a ser artículos de datos?}

Manuscritos que describan conjuntos de datos primarios y originales que contengan registros biológicos (captura de datos de la presencia de un(os) organismo(s) en un lugar y tiempo determinados); información asociada a ejemplares de colecciones biológicas; listados temáticos o geográficos de especies; datos genómicos y todos aquellos datos que sean susceptibles de ser

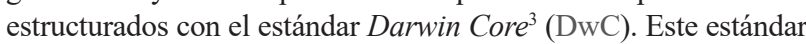
es utilizado dentro de la comunidad de autores que publican conjuntos de datos sobre biodiversidad para estructurar los datos y de esta manera poder consolidarlos e integrarlos desde diferentes fuentes a nivel global. No se recomienda someter manuscritos que describan conjuntos de datos secundarios, como por ejemplo compilaciones de registros biológicos desde fuentes secundarias (p.e. literatura o compilaciones de registros ya publicados en redes como GBIF o IABIN).

\section{Preparación de los datos}

Como se mencionó anteriormente los datos sometidos dentro de este proceso deben ser estructurados en el estándar DwC. Para facilitar su estructuración, el Sistema de Información sobre Biodiversidad de Colombia (SiB Colombia), ha creado dos plantillas en Excel, una para registros biológicos y otra para listas de especies. Lea y siga detenidamente las instrucciones de las plantillas para la estructuración de los datos a publicar. Para cualquier duda sobre el proceso de estructuración de estos datos por favor contactar al equipo coordinador del SiB Colombia (ECSiB) en sib+iac@humboldt.org.co.

\footnotetext{
${ }^{1}$ Wieczorek, J. 2011. Perfil de Metadatos de GBIF: una guía de referencia rápida. En: Wieczorek, J. The GBIF Integrated Publishing Toolkit User Manual, version 2.0. Traducido y adaptado del inglés por D. Escobar. Sistema de Información sobre Biodiversidad de Colombia, Bogotá D.C., Colombia, 23p. Disponible en http://www.sibcolombia.net/repositorio-de-documentos.

${ }^{2}$ Chavan, V. y L. Penev. 2011. The data paper: The mechanism to incentivize data publishing in biodiversity science. BMC Bioinformatics 12 (Suppl 15): S2.

${ }^{3}$ TDWG. 2011. Darwin Core: una guía de referencia rápida. (Versión original producida por TDWG, traducida al idioma español por Escobar, D.; versión 2.0). Bogotá: SiB Colombia, 33 pp. Disponible en http://www.sibcolombia.net/repositorio-de-documentos
} 


\section{Preparación del manuscrito}

Para facilitar la creación y estructuración del manuscrito en el estándar GMP, se cuenta con la ayuda de un editor electrónico (http://ipt.sibcolombia.net/biota) que guiará al autor en dicho proceso y que finalmente generará una primera versión del manuscrito. Se recomienda el uso del manual GMP, como una guía de la información a incluir en cada sección del manuscrito, junto con el anexo 1 .

Pasos a seguir para la elaboración del manuscrito:

1 Solicite al correo sib+iac@humboldt.org.co el acceso al editor electrónico. El EC-SiB le asignará un usuario y contraseña.

2. Ingrese con su usuario y contraseña al editor electrónico, luego diríjase a la pestaña Gestión de recursos y cree un nuevo recurso asignando un nombre corto a su manuscrito usando el formato "AcrónimoDeLaInstitución_año_tipoDeConjuntoDeDatos", p.e. ABC_2010_avestinije y dar clic en el botón crear.

3. En la vista general del editor seleccione "editar" en la pestaña Metadatos (por favor, no manipule ningún otro elemento), allí encontrará diferentes secciones (panel derecho) que lo guiarán en la creación de su manuscrito. Guarde los cambios al finalizar cada sección, de lo contrario perderá la información. Recuerde usar el manual GMP. A continuación se presentan algunas recomendaciones para la construcción del manuscrito. Las secciones se indican en MAYUSCULAS y los elementos de dichas secciones en negrilla.

- En PARTES ASOCIADAS incluya únicamente aquellas personas que no haya incluido en INFORMACIÓN BÁSICA.

- Los DATOS DEL PROYECTO y DATOS DE LA COLECCIÓN son opcionales según el tipo de datos. En caso de usar dichas secciones amplíe o complemente información ya suministrada, p. ej. no repita información de la descripción (COBERTURA GEOGRÁFICA) en la descripción del área de estudio (DATOS DEL PROYECTO).

- De igual manera, en los MÉTODOS DE MUESTREO, debe ampliar o complementar información, no repetirla. La información del área de estudio debe dar un contexto específico a la metodología de muestreo.

- Es indispensable documentar el control de calidad en MÉTODOS DE MUESTREO. Acá se debe describir que herramientas o protocolos se utilizaron para garantizar la calidad y coherencia de los datos estructurados con el estándar DwC.

- Para crear la referencia del recurso, en la sección REFERENCIAS, utilice uno de los dos formatos propuestos (Anexo 2). No llene el identificador de la referencia, este será suministrado posteriormente por el EC-SiB.

- Para incluir la bibliografía del manuscrito en referencias, ingrese cada una de las citas de manera individual, añadiendo una nueva referencia cada vez haciendo clic en la esquina inferior izquierda.

4. Rectifique que el formato de la información suministrada cumpla con los lineamientos de la revista (p. ej. abreviaturas, unidades, formato de números etc.) en la Guía general para autores de Biota Colombiana.

5. Una vez incluida y verificada toda la información en el editor electrónico notifique al EC-SiB al correo electrónico sib+iac@ humboldt.org.co, indicando que ha finalizado la edición del manuscrito. Adicionalmente adjunte la plantilla de Excel con los datos estructurados (elimine todas las columnas que no utilizó). El EC-SiB realizará correcciones y recomendaciones finales acerca de la estructuración de los datos y dará las instrucciones finales para que usted proceda a someter el artículo.

\section{Someter el manuscrito}

Una vez haya terminado la edición de su manuscrito y recibido las instrucciones por parte del EC-SIB, envíe una carta al correo electrónico biotacol@humboldt.org.co para someter su artículo, siguiendo las instrucciones en la Guía general para autores de Biota Colombiana.

Recuerde adjuntar:

- Plantilla de Excel con la última versión de los datos revisada por el EC-SiB.

- Documento de Word con las figuras y tablas seguidas de una lista las mismas.

Cuando finalice el proceso, sus datos se harán públicos y de libre acceso en los portales de datos del SiB Colombia y GBIF. Esto permitirá que sus datos estén disponibles para una audiencia nacional e internacional, manteniendo siempre el crédito para los autores e instituciones asociadas. 
Anexo 1. Estructura base de un artículo de datos y su correspondencia con el editor electrónico basado en el GMP.

\begin{tabular}{|c|c|}
\hline SECCIÓN/SUBSECCIÓN & CORRESPONDENCIA CON LOS ELEMENTOS DEL EDITOR ELECTRÓNICO \\
\hline TÍTUlo & Derivado del elemento título. \\
\hline AutORES & Derivado de los elementos creador del recurso, proveedor de los metadatos y partes asociadas. \\
\hline AFILIACIONES & $\begin{array}{l}\text { Derivado de los elementos creador del recurso, proveedor de los metadatos y partes asociadas. } \\
\text { De estos elementos, la combinación de organización, dirección, código postal, ciudad, país y } \\
\text { correo electrónico, constituyen la afiliación. }\end{array}$ \\
\hline AUTOR DE CONTACTO & Derivado de los elementos creador del recurso y proveedor de los metadatos. \\
\hline Citación & Para uso de los editores. \\
\hline CitACIÓN DELE RECURSO & Derivada del elemento referencia del recurso. \\
\hline RESUMEN & Derivado del elemento resumen. Máximo 200 palabras. \\
\hline Palabras clave & Derivadas del elemento palabras clave. Máximo seis palabras. \\
\hline ABSTRACT & Derivado del elemento abstract. Máximo 200 palabras. \\
\hline KEY WORDS & Derivadas del elemento key words. Máximo seis palabras. \\
\hline INTRODUCCIÓN & $\begin{array}{l}\text { Derivado del elemento propósito (de las secciones Introducción y Antecedentes). Se sugiere un } \\
\text { breve texto para introducir las siguientes secciones. Por ejemplo, historia o contexto de la colección } \\
\text { biológica o proyecto en relación con los datos descritos, siempre y cuando no se repita información } \\
\text { en las subsecuentes secciones. }\end{array}$ \\
\hline Datos del proyecto & $\begin{array}{l}\text { Derivada de los elementos de la sección Datos del proyecto: título, nombre, apellido, rol, fuentes } \\
\text { de financiación, descripción del área de estudio y descripción del proyecto. }\end{array}$ \\
\hline Cobertura taxonómica & $\begin{array}{l}\text { Derivada de los elementos de la sección Cobertura taxonómica: descripción, nombre científico, } \\
\text { nombre común y categoría. }\end{array}$ \\
\hline Cobertura geográfica & $\begin{array}{l}\text { Derivada de los elementos de la sección Cobertura geográfica: descripción, latitud mínima, } \\
\text { latitud máxima, longitud mínima, longitud máxima. }\end{array}$ \\
\hline Cobertura temporal & Derivada de los elementos de la sección Cobertura temporal: tipo de cobertura temporal. \\
\hline Datos de la colección & $\begin{array}{l}\text { Derivada de los elementos de la sección Datos de la colección: nombre de la colección, } \\
\text { identificador de la colección, identificador de la colección parental, método de preservación } \\
\text { de los especímenes y unidades curatoriales. }\end{array}$ \\
\hline MATERIAL Y MÉTODOS & $\begin{array}{l}\text { Derivado de los elementos de la sección Métodos de muestreo: área de estudio, descripción del } \\
\text { muestreo, control de calidad, descripción de la metodología paso a paso. }\end{array}$ \\
\hline \multicolumn{2}{|l|}{ RESUltados } \\
\hline Descripción del conjunto de datos & $\begin{array}{l}\text { Derivado de los elementos de las secciones Discusión y Agradecimientos, contiene información } \\
\text { del formato de los datos y metadatos: nivel de jerarquía, fecha de publicación y derechos de } \\
\text { propiedad intelectual. }\end{array}$ \\
\hline Discusión & $\begin{array}{l}\text { Se deriva del elemento discusión. Un texto breve (máximo } 500 \text { palabras), que puede hacer } \\
\text { referencia a la importancia, relevancia, utilidad o uso que se le ha dado o dará a los datos en } \\
\text { publicaciones existentes o en posteriores proyectos. }\end{array}$ \\
\hline AGRADECIMIENTOS & Se deriva del elemento agradecimientos. \\
\hline BiBLIOGRAFÍA & Derivado del elemento bibliografía. \\
\hline
\end{tabular}


Anexo 2. Formatos para llenar el elemento referencia del recurso.

La referencia del recurso es aquella que acompañará los datos descritos por el artículo, públicos a través de las redes SiB Colombia y GBIF. Tenga en cuenta que esta referencia puede diferir de la del artículo. Para mayor información sobre este elemento contacte al EC-SiB. Aquí se sugieren dos formatos, sin embargo puede consultar otros formatos establecidos por $\mathrm{GBIF}^{4}$.

\section{TIPO DE RECURSO}

El conjunto de datos que el manuscrito describe es resultado de un proyecto de carácter institucional o colectivo con múltiples participantes.

\section{PLANTILLA}

$<$ Institución publicadora/ Grupo de investigación $>$ $<$ (Año) $>$, $<$ Título del recurso/Artículo $>$. $<$ Número total de registros $>$, <aportados por: $><$ parte asociada 1 (rol), parte asociada $2(\mathrm{rol})(\ldots)>$. $<$ En línea, $><$ url del recurso $>$. $<$ Publicado el DD/MM/ AAAA $>$.

\section{EJEMPLO}

Centro Nacional de Biodiversidad (2013). Vertebrados de la cuenca de la Orinoquia. 1500 registros, aportados por Pérez, S. (Investigador principal, proveedor de contenidos, proveedor de metadatos), M. Sánchez (Procesador), D. Valencia (Custodio, proveedor de metadatos), R. Rodríguez (Procesador), S. Sarmiento (Publicador), V. B. Martínez (Publicador, editor). En línea, http://ipt.sibcolombia.net/biota/resource.do?r=verte_orin, publicado el 01/09/2013.

Valencia, D., R. Rodríguez y V. B. Martínez (2013). Vertebrados de la cuenca del Orinoco. 1500 registros, en línea, http://ipt.sibcolombia.net/biota/ resource.do?r=verte orin. Publicado el 01/09/2001.
El conjunto de datos que el manuscrito describe es resultado de una iniciativa personal o de un grupo de investigación definido.
$<$ Parte asociada 1, parte asociada $2(\ldots)>$ $<$ (Año) $>$, $<$ Título del recurso/Artículo $>$, $<$ Número total de registros $>$, <en línea, $><$ url del recurso $>$. $<$ Publicado el DD/MM/AAAA $>$

\section{Guidelines for authors - Data Papers}

www.humboldt.org.co/es/bibliotecaypublicaciones/biota- biotacol@humboldt.org.co|

www.sibcolombia.net - sib+iac@humboldt.org.co

The purpose of this guide is to establish and explain the necessary steps to prepare a manuscript with the potential to become a publishable data paper in Biota Colombiana. This guide includes aspects related to the preparation of both data and the manuscript.

\section{What is a Data Paper?}

A data paper is a scholarly publication that has emerged as a mechanism to encourage the publication of biodiversity data as well as an approach to generate appropriate academic and professional recognition to all those involved in in the management of biodiversity information.

A data paper contains the basic sections of a traditional scientific paper. However, these are structured according to an international standard for metadata (information that gives context to the data) known as the GBIF Metadata Profile (GMP)5. The structuring of the manuscript based on this standard enables the community of authors publishing datasets globally, with presence in networks such as the Global Biodiversity Information Facility (GBIF) and other related networks, to publish data easily while getting proper recognition for their work and to encourage the authors of this type of data sets that have not yet published in these global information networks to have the necessary incentives to do so.

A data paper should describe in the best possible way the Whom, What, Where, When, Why and How of documenting and recording of data, without becoming the instrument to make a detailed analysis of the data, as happens in other academic publications. To deepen this publishing model, it is recommended to consult Chavan \& Penev (2011) ${ }^{6}$.

\footnotetext{
${ }^{4}$ GBIF (2012). Recommended practices for citation of the data published through the GBIF Network. Version 1.0 (Authored by Vishwas Chavan), Copenhagen: Global Biodiversity Information Facility. Pp.12, ISBN: 87-92020-36-4. Accessible at http://links.gbif.org/gbif_best_practice_data_citation_ en_v1

${ }^{5}$ GBIF (2011). GBIF Metadata Profile, Reference Guide, Feb 2011, (contributed by O Tuama, E., Braak, K., Copenhagen: Global Biodiversity Information Facility,19 pp. Accesible at http://links.gbif.org/gbif_metadata_profile_how-to_en_v1.

${ }^{6}$ Chavan, V. y L. Penev. 2011. The data paper: The mechanism to incentivize data publishing in biodiversity science. BMC Bioinformatics 12 (Suppl 15): S2.
} 
Guía para aut ores - Artículos de Datos / Guidelines for authors - Data Papers

\section{Which manuscripts are suitable for publication as data paper?}

Manuscripts that describe datasets containing original primary biological records (data of occurrences in a particular place and time); information associated with specimens of biological collections, thematic or regional inventories of species, genomic data and all data likely to be structured with the standard Darwin CoreDarwin Core $^{7}$ (DwC). This standard is used in the community of authors publishing biodiversity datasets to structure the data and thus to consolidate and integrate from different sources globally. It is not recommended to submit manuscripts describing secondary datasets, such as biological records compilations from secondary sources (e.g. literature or compilations of records already published in networks such as GBIF or IABIN).

\section{Dataset preparation}

As mentioned above data submitted in this process should be structured based on DwC standard. For ease of structuring, the Biodiversity Information System of Colombia (SiB Colombia), created two templates in Excel; one for occurrences and other for species checklist. Carefully read and follow the template instructions for structuring and publishing data. For any questions about the structure process of data please contact the Coordinator Team of SiB Colombia (EC-SiB) at sib+iac@humboldt.org.co

\section{Manuscript preparation}

To assist the creation and structuring of the manuscript in the GMP standard, an electronic writing tool is available (http://ipt. sibcolombia.net/biota) to guide the author in the process and ultimately generate a first version of the manuscript. The use of GMP manual as an information guide to include in each section of the manuscript, as well as the annex 1 is recommended.

Steps required for the manuscript preparation:

1 Request access to the electronic writing tool at sib+iac@ humboldt.org.co. The EC-SiB will assign a username and password.

2. Login to the electronic writing tool, then go to the tab Manage Resources and create a new resource by assigning a short name for your manuscript and clicking on the Create button. Use the format: "InstitutionAcronym_Year_DatasetFeature", e.g. NMNH 2010 rainforestbirds.

3. In the overview of the writing tool click on edit in Metadata section (please, do not use any other section), once there you will find different sections (right panel) that will guide you creating your manuscript. Save the changes at the end of each section, otherwise you will lose the information. Remember to use the GMP manual. Here are some recommendations for editing the metadata, sections are indicated in CAPS and the elements of these sections in bold.
- In ASSOCIATED PARTIES include only those who are not listed in BASIC INFORMATION.

- PROJECT DATA and COLLECTION DATA are optional depending on the data type. When using these sections extend or complement information already provided, i.e. do not repeat the same information describing the description (GEOGRAPHIC COVERAGE) in the study area description (PROJECT DATA).

- Likewise, in SAMPLING METHODS, you must expand or complete the information, not repeat it. The information in study extent should give a specific context of the sampling methodology.

- It is essential to document the quality control in SAMPLING METHODS. Here you should describe what tools or protocols were used to ensure the quality and consistency of data structured with DwC standard.

- To create the resource citation in the CITATIONS section, follow one of the two formats proposed (Annex 2). Do not fill out the citation identifier, this will be provided later by the EC-SiB.

- To include the manuscript bibliography in citations, enter each of the citations individually, adding a new citation each time by clicking in the bottom left.

4. Check that the format of the information provided meets the guidelines of the journal (e.g. abbreviations, units, number formatting, etc.) in the Biota Colombiana Guidelines for Authors.

5. Once included and verified all information in the writing tool, notify to EC-SiB at sib+iac@humboldt.org.co, indicating that you have finished editing the manuscript. Additionally attach the Excel template with structured data (remove all columns that were not used). The EC-SiB will perform corrections and final recommendations about the structure of the data and give you the final instructions to submit the paper.

\section{Submit the manuscript}

Once you have finished editing your manuscript and getting the instructions from EC-SIB, send a letter submitting your article to email biotacol@humboldt.org.co, following the instructions of Biota Colombiana Guidelines for Authors.

Remember to attach:

- Excel template with the latest version of the data reviewed by the EC-SiB.

- Word document with figures and tables followed by a list of them.

At the end of the process, your information will be public and freely accessible in the data portal of SiB Colombia and GBIF. This will allow your data to be available for national and international audience, while maintaining credit to the authors and partner institutions.

\footnotetext{
${ }^{7}$ Biodiversity Information Standards - TDWG. Accesible at http://rs.tdwg.org/dwc/terms/
} 
Annex 1. Basic structure of a data paper and its mapping to the writing tool elements based on GM.

\begin{tabular}{|c|c|}
\hline $\begin{array}{l}\text { SECTION/SUB-SECTION } \\
\text { HEADING }\end{array}$ & MAPPING WITH WRITING TOOL ELEMENTS \\
\hline TITLE & Derived from the title element. \\
\hline Authors & Derived from the resource creator, metadata provider, and associated parties elements. \\
\hline AfFILIATIONS & $\begin{array}{l}\text { Derived from the resource creator, metadata provider and associated parties elements. From } \\
\text { these elements combinations of organization, address, postal code, city, country and email } \\
\text { constitute the affiliation. }\end{array}$ \\
\hline CORRESPONDING AUTHOR & Derived from the resource contact, metadata provider elements. \\
\hline Citation & For editors use. \\
\hline RESOURCE CITATION & Derived from the resource citation element. \\
\hline RESUMEN & Derived from the resumen element. 200 words max. \\
\hline Palabras Clave & Derived from the palabras clave element. 6 words max. \\
\hline ABSTRACT & Derived from the abstract element. 200 words max. \\
\hline KEY WORDS & Derived from the key words element. 6 words max. \\
\hline INTRODUCTION & $\begin{array}{l}\text { Derived from the purpose (Introduction and Background section). A short text to introduce the } \\
\text { following sections is suggested. For example, history or context of the biological collection or } \\
\text { project related with the data described, only if that information is not present in subsequent sections. }\end{array}$ \\
\hline Project data & $\begin{array}{l}\text { Derived from elements title, personnel first name, personnel last name, role, funding, study } \\
\text { area description, and design description. }\end{array}$ \\
\hline Taxonomic Coverage & $\begin{array}{l}\text { Derived from the taxonomic coverage elements: description, scientific name, common name } \\
\text { and rank. }\end{array}$ \\
\hline Geographic Coverage & Derived from the geographic coverage elements: description, west, east, south, north. \\
\hline Temporal Coverage & Derived from the temporal coverage elements: temporal coverage type. \\
\hline Collection data & $\begin{array}{l}\text { Derived from the collection data elements: collection name, collection identifier, parent } \\
\text { collection identifier, specimen preservation method and curatorial units. }\end{array}$ \\
\hline MATERIALS AND METHODS & $\begin{array}{l}\text { Derived from the sampling methods elements: study extent, sampling description, quality } \\
\text { control and step description. }\end{array}$ \\
\hline \multicolumn{2}{|l|}{ RESUltados } \\
\hline Descripción del conjunto de datos & $\begin{array}{l}\text { Derived from the discussion and acknowledgments, contains information about the format of the } \\
\text { data and metadata: hierarchy level, date published and ip rights. }\end{array}$ \\
\hline DisCUSSION & $\begin{array}{l}\text { Derived from the discussion element. A short text ( } \max 500 \text { words), which can refer to the } \\
\text { importance, relevance, usefulness or use that has been given or will give the data in the published } \\
\text { literature or in subsequent projects. }\end{array}$ \\
\hline ACKNOWLEDGMENTS & Derived from the acknowledgments element. \\
\hline BIBLIOGRAPHY & Derived from the citations element. \\
\hline
\end{tabular}


Annex 2. Citation style quick guide for "resource reference" section.

The Resource Reference is the one that refer to the dataset described by the paper, publicly available through SiB Colombia and GBIF networks. Note that this reference may differ from the one of the paper. For more information about this element contact EC-SiB.

Here two formats are suggested; however you can consult other formats established by GBIF .

\section{TYPE OF RESOURCE}

The paper is the result of a collective or institutional project with multiple participants.

The paper is the result of a personal initiative or a defined research group.

\section{TEMPLATE}

$<$ Institution/Research Group $>$. < Year $>,<$ Title of the Resource/Paper $>$. $<$ Number of total records $>$, <provided by :> <associated party 1 (role), associated party 2 (role), (...) > $<$ Online, $>$ $<$ resource URL $>$, $<$ published on $>$. $<$ Published on DD/MM/AAAA $>$.

$<$ associated party 1 , associated party $2,(\ldots)>$. $<$ Year $>$, $<$ Title of the Resource/Paper $>$, $<$ Number of total records $>,<$ Online, $><$ resource URL $>$. $<$ Published on DD/MM/AAAA $>$.

\section{EXAMPLE}

National Biodiversity (2013). Vertebrates in Orinoco, 1500 records, provided by: Perez, S. (Principal investigator, content provider), M. Sanchez (Processor), D. Valencia (Custodian Steward, metadata provider), R. Rodriguez (Processor), S. Sarmiento (Publisher), VB Martinez (Publisher, Editor). Online, http://ipt.sibcolombia.net/ biota/resource.do? $\mathrm{r}=$ verte orin, published on 01/09/2013.

Valencia, D., R. Rodríguez and V. B. Martínez. (2013). Vertebrate Orinoco Basin, 1500 records, Online, http://ipt.sibcolombia.net/biota/resource. do? $\mathrm{r}=$ verte_orin, published on 01/09/2001

${ }^{8}$ GBIF (2012). Recommended practices for citation of the data published through the GBIF Network. Version 1.0 (Authored by Vishwas Chavan), Copenhagen: Global Biodiversity Information Facility. Pp.12, ISBN: 87-92020-36-4. Accessible at http://links.gbif.org/gbif_best practice_data_citation en $\mathrm{v} 1$ 


\section{TABLA DE CONTENIDO / TABLE OF CONTENTS}

Aguas subterráneas, humedales y servicios ecosistémicos en Colombia. Groundwater, wetlands and ecosystem services in Colombia. Teresita Betancur-Vargas, Daniel A. García-Giraldo, Angélica J. Vélez-Duque, Angélica M. Gómez, Carlos Flórez-Ayala, Jorge Patiño y Juan Á. Ortiz-Tamayo

Efecto del $\mathrm{CaCl}_{2}$ sobre el contenido de proteínas, prolina, acidez titulable, clorofila y contenido relativo de agua de $A$ loe vera expuesta a salinidad por $\mathrm{NaCl}$. $\mathrm{CaCl}_{2}$ effect on protein, proline, titratable acidity, chlorophyll and relative water content from Aloe vera exposed to salinity by NaCl. Selwin Pérez-Nasser .... Efecto del $\mathrm{Ca}^{2+}$ sobre algunas variables de crecimiento de Aloe vera cultivada con $\mathrm{NaCl}$. Effect of $\mathrm{Ca}^{2+}$ on some growth variables from Aloe vera grown on $\mathrm{NaCl}$. Selwin Pérez-Nasser

Charophyta, Chlorophyta y Cryptophyta del embalse Riogrande II (Antioquia), Colombia. Charophyta, Chlorophyta and Cryptophyta in Riogrande II reservoir (Antioquia), Colombia. Mónica T. López Muñoz, Carlos E. De Mattos-Bicudo, Ricardo O. Echenique, John J. Ramírez-Restrepo y Jaime A. Palacio ................ Diferencias del contenido nutricional de hojas jóvenes y maduras de dos especies de puya (Puya santosii Cuatrec., Puya goudotiana Mez; Bromeliaceae), en la región del Guavio, Cundinamarca, Colombia. Differences in the nutritional content of mature and young Puya leaves (Puya santosii Cuatrec., Puya goudotiana Mez; Bromeliaceae) in the Guavio region, Cundinamarca, Colombia. Luis J. Romero-Puentes, Brayan L. Torres-Clavijo y Angela ParradoRosselli

Características físicas y germinativas de semillas de la orquídea Prosthechea sp. de la zona andina, Fusagasugá, Colombia. Physical and germinative characteristics of Prosthechea sp. (Orchidaceae) native to Fusagasugá - Colombia. Laguandio del C. Banda-Sánchez, Yeison H. Pinzón-Ariza y Luis E. Vanegas-Martínez

Especies vegetales colonizadoras de áreas perturbadas por la minería en bosques pluviales del Chocó, Colombia. Colonizer plant species of sites disturbed by mining in the Chocoan rain forests, Colombia. Hamleth Valois-Cuesta y Carolina Martinez-Ruiz

Catálogo de la flora vascular de los Parques Nacionales de Colombia: Santuario de Flora y Fauna de Iguaque y su zona de amortiguamiento. Catalog of the vascular flora of the National Parks of Colombia: Iguaque Fauna and Flora Sanctuary and buffer zone. Humberto Mendoza-Cifuentes .....

Cambios estructurales del mesozooplancton en relación a las condiciones hidrográficas en el golfo de Cariaco, Venezuela. Structural changes of mesozooplankton in relation to hydrographic conditions in the Gulf of Cariaco, Venezuela. Brightdoom Márquez-Rojas, Evelyn Zoppi de Roa, Luis Troccoli y Edy Montiel

Chinches patinadoras marinas (Hemiptera: Heteroptera: Gerromorpha): diversidad de los hábitats oceánicos del Neotrópico. Marine water striders (Hemiptera: Heteroptera: Gerromorpha): diversity of ocean habitats in the Neotropics. Fredy Molano-Rendón e Irina Morales

Descripción de una nueva especie de mariposa del género Wahydra Steinhauser (Lepidoptera: Hesperiidae: Hesperiinae: Anthoptini) para Colombia. Description of a new species of butterfly of the genus Wahydra Steinhauser (Lepidoptera: Hesperiidae: Hesperiinae: Anthoptini) from Colombia. Efrain R. Henao-Bañol, Fabián G. Gaviria y Julián A. Salazar-Escobar

Pseudoescorpiones (Arachnida: Pseudoscorpiones) del nororiente andino de Colombia. Pseudoscorpions (Arachnida: Pseudoscorpiones) in the norteastern Andean region of Colombia. Catalina Romero-Ortiz

Primer registro de cuatro especies de camarones de agua dulce (Palaemonidae) para Colombia. First records of four species of freshwater shrimp (Palaemonidae) from Colombia. Ada Acevedo y Carlos A. Lasso

Lista anotada de los tipos de peces en la colección del Laboratorio de Ictiología, Universidad del Quindío, Armenia, Colombia (IUQ). Annotated list of types of fishes in the collection of the Laboratory of Ichthyology, University of Quindío, Armenia, Colombia (IUQ). César Román-Valencia, Donald C. Taphorn, Carlos. A. García-Alzate, Sebastián Vásquez-P. y Raquel I. Ruiz-C........

Pterygoplichthys undecimalis (Siluriformes: Loricariidae): una especie trasplantada en la cuenca del río Patía, vertiente Pacífico, Colombia. Pterygoplichthys undecimalis (Siluriformes: Loricariidae): a species transplanted to the Basin of the Patía River, Colombia. Alberto Moncayo-Fernández, Ofelia Mejía-Egas y Héctor E. Ramirez-Chaves

Lista anotada de la herpetofauna del departamento del Quindío, Colombia. Checklist of the herpetofauna of the department of Quindío, Colombia. Cristian Román-Palacios, Sara Fernández-Garzón, Alejandro Valencia-Zuleta, Andrés F. Jaramillo-Martínez y Ronald A. Viáfara-Vega

Batracofauna de los bosques de niebla y estribaciones del piedemonte en el municipio de Yopal (Casanare), Orinoquia colombiana. Frogs and toads of cloud forests and foothills in the Yopal municipality (Casanare), Colombia. Andrés R. Acosta-Galvis

Jagüeyes y su papel potencial en la conservación de tortugas continentales en el golfo de Morrosquillo, Sucre, Caribe colombiano. Cattle ponds and their potential role in conservation of freshwater turtles in the Gulf of Morrosquillo, Sucre, Colombia. Jaime De La Ossa-V., Merly Ardila-Marulanda, Alejandro De La Ossa-Lacayo

Aspectos poblacionales de primates diurnos simpátricos que habitan parches de bosque seco tropical en los Montes de María, Sucre, Colombia. Populational aspects of diurnal sympatric primates inhabiting patches of tropical dry forest in the Montes de María, Sucre, Colombia. Jaime De La Ossa-V. $y$ Silvia Galván-Guevara

Diversidad de pequeños mamíferos no voladores (Didelphimorphia, Paucituberculata y Eulipotyphla) en Áreas de Protección Estricta de Venezuela. Diversity of non-volant small mammals (Didelphimorphia, Paucituberculata and Eulipotyphla) in the Strictly Protected Areas in Venezuela. Franger J. García, Mariana I. Delgado-Jaramillo y Marjorie Machado

La integridad biológica como herramienta de valoración cuantitativa del estado de conservación del bosque seco en Colombia. Biological integrity as a tool for quantitative assessment of the conservation status of dry forest in Colombia. Wilmar Bolivar-García, Alan Giraldo y Ángela M. González-Colorado

Nota

Ampliación de la distribución geográfica de Microgenys minuta Eigenmann 1913 (Characiformes, Characidae) en la cuenca del río Magdalena, Colombia. Expansion of distribution of Microgenys minuta Eigenmann 1913 (Characiformes, Characidae) in the Magdalena River basin, Colombia. Lina M. Mesa-S. $y$ Juan G. Albornoz

\section{Artículo de datos}

Colección Ictiológica de la Universidad Industrial de Santander, Colombia. Ichthyology Collection of the Industrial University of Santander, Colombia. Mauricio Torres, Egna Mantilla-Barbosa, Federico Rangel-Serpa.....

Guía para autores. Guidelines for authors 